\title{
Improved Phased Array Imaging of a Model Jet
}

Robert P. Dougherty

OptiNav, Inc., Redmond, Washington

Gary G. Podboy

Glenn Research Center, Cleveland, Ohio 


\section{NASA STI Program . . . in Profile}

Since its founding, NASA has been dedicated to the advancement of aeronautics and space science. The NASA Scientific and Technical Information (STI) program plays a key part in helping NASA maintain this important role.

The NASA STI Program operates under the auspices of the Agency Chief Information Officer. It collects, organizes, provides for archiving, and disseminates NASA's STI. The NASA STI program provides access to the NASA Aeronautics and Space Database and its public interface, the NASA Technical Reports Server, thus providing one of the largest collections of aeronautical and space science STI in the world. Results are published in both non-NASA channels and by NASA in the NASA STI Report Series, which includes the following report types:

- TECHNICAL PUBLICATION. Reports of completed research or a major significant phase of research that present the results of NASA programs and include extensive data or theoretical analysis. Includes compilations of significant scientific and technical data and information deemed to be of continuing reference value. NASA counterpart of peer-reviewed formal professional papers but has less stringent limitations on manuscript length and extent of graphic presentations.

- TECHNICAL MEMORANDUM. Scientific and technical findings that are preliminary or of specialized interest, e.g., quick release reports, working papers, and bibliographies that contain minimal annotation. Does not contain extensive analysis.

- CONTRACTOR REPORT. Scientific and technical findings by NASA-sponsored contractors and grantees.
- CONFERENCE PUBLICATION. Collected papers from scientific and technical conferences, symposia, seminars, or other meetings sponsored or cosponsored by NASA.

- SPECIAL PUBLICATION. Scientific, technical, or historical information from NASA programs, projects, and missions, often concerned with subjects having substantial public interest.

- TECHNICAL TRANSLATION. Englishlanguage translations of foreign scientific and technical material pertinent to NASA's mission.

Specialized services also include creating custom thesauri, building customized databases, organizing and publishing research results.

For more information about the NASA STI program, see the following:

- Access the NASA STI program home page at http://www.sti.nasa.gov

- E-mail your question via the Internet to help@ sti.nasa.gov

- Fax your question to the NASA STI Help Desk at $443-757-5803$

- Telephone the NASA STI Help Desk at 443-757-5802

- Write to: NASA Center for AeroSpace Information (CASI) 7115 Standard Drive Hanover, MD 21076-1320 


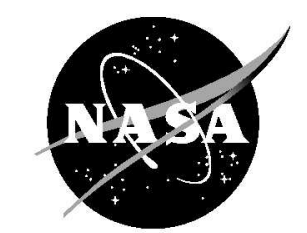

\section{Improved Phased Array Imaging of a Model Jet}

Robert P. Dougherty

OptiNav, Inc., Redmond, Washington

Gary G. Podboy

Glenn Research Center, Cleveland, Ohio

Prepared for the

15th Aeroacoustics Conference (30th Aeroacoustics Conference) cosponsored by AIAA and CEAS

Miami, Florida, May 11-13, 2009

National Aeronautics and

Space Administration

Glenn Research Center Cleveland, Ohio 44135 


\section{Acknowledgments}

This work was supported by the NASA NRA Contract NNC07CB02C "Improved Phased Array Techniques to Account for Extended Sources of Fan and Jet Noise."

Trade names and trademarks are used in this report for identification only. Their usage does not constitute an official endorsement, either expressed or implied, by the National Aeronautics and Space Administration.

This work was sponsored by the Fundamental Aeronautics Program at the NASA Glenn Research Center.

Level of Review: This material has been technically reviewed by technical management.

Available from

NASA Center for Aerospace Information 7115 Standard Drive

Hanover, MD 21076-1320
National Technical Information Service 5301 Shawnee Road Alexandria, VA 22312

Available electronically at http://gltrs.grc.nasa.gov 


\title{
Improved Phased Array Imaging of a Model Jet
}

\author{
Robert P. Dougherty \\ OptiNav, Inc. \\ Redmond, Washington 98052 \\ Gary G. Podboy \\ National Aeronautics and Space Administration \\ Glenn Research Center \\ Cleveland, Ohio 44135
}

\begin{abstract}
An advanced phased array system, OptiNav Array 48, and a new deconvolution algorithm, TIDY, have been used to make octave band images of supersonic and subsonic jet noise produced by the NASA Glenn Small Hot Jet Rig (SHJAR). The results are much more detailed than previous jet noise images. Shock cell structures and the production of screech in an underexpanded supersonic jet are observed directly. Some trends are similar to observations using spherical and elliptic mirrors that partially informed the two-source model of jet noise, but the radial distribution of high frequency noise near the nozzle appears to differ from expectations of this model. The beamforming approach has been validated by agreement between the integrated image results and the conventional microphone data.
\end{abstract}

\section{Introduction}

Jet noise remains interesting after many years of study, despite a complete lack of hardware in the noise-producing region. The simplest case, a single-flow round jet with no forward flight, can produce a range of noise source phenomena: turbulent shear flow, mixing noise from large scale coherent structures, broadband shock associated noise, and screech tones (Ref. 1). These have been studied by measuring directivity in the far field, the acoustic pressure distribution in the near field, microphone two-point correlation, and spherical and elliptic mirror imaging (Ref. 2). Shock cells occur in the supersonic case when the jet is not ideally expanded. Flow disturbances convecting through the shock cells give rise to broadband shock-associated noise and screech tones (Refs. 3 and 4). Shock-associated noise can be identified in far-field spectra as an excess above the mixing noise that follows a well-defined correlation (Ref. 5). The shock cell structure can be imaged with Schlieren photography and its fluctuations have been studied with optical deflectrometry (Ref. 6) and numerical methods (Refs. 7 and 8).

Several studies of jet noise using phased arrays and related systems of microphone arrays have been made (Refs. 9 to 18). These measurements have frequently been limited to subsonic jets, and have had several drawbacks that prevent the structure of the jet noise source from being fully revealed. Onedimensional arrays (Refs. 9, 14, and 18) do not readily show the radial structure of the source. Cage arrays (Refs. 10, 12, and 15) are designed for three-dimensional imaging, but they have several drawbacks. They subtend an angle that is too large to illustrate the source for different directivity angles. Their location in the near field can give confusing results. Finally, the large separation of the microphones produces severe problems with turbulent decorrelation.

Phased array studies of jet noise have been criticized on the basis that the monopole source model used in beamforming is too simplistic. This issue has been addressed by Michel (Ref. 19), who showed that jet source convection and correlation length effects can be reduced to simple sources with directivity patterns. The use of a phased array is therefore justified, provided that it subtends a reasonably small range of solid angle. A similar argument was made to justify mirror studies of jets in the 1970s (Ref. 20). A straightforward but conservative specification would be to require that the array is small enough that its Rayleigh resolution spot size is larger than the presumed correlation length of the turbulence. The Rayleigh resolution of imaging system of this type (essentially a microscope) is 


$$
r_{1}=0.61 \frac{\lambda}{N A}
$$

where $\lambda$ is the acoustic wavelength and $N A$ is the numerical aperture, the sine of the half angle of the aperture subtended by the array. To first order in the subtended angle, the limit on the array aperture could be expressed as

$$
\text { aperture }<2.44 \frac{R \lambda}{\Lambda}
$$

where $R$ is the distance from the array to the jet and $\Lambda$ is the turbulence correlation length. The TIDY algorithm discussed below improves the array resolution by a factor of three. It is an open question whether this means the array must be made smaller to avoid erroneous results from extended correlation.

Improved array designs and beamforming methods have been developed. In order to study the jet noise in this context, a test was conducted in the NASA Glenn Aero-Acoustic Propulsion Laboratory (AAPL) using an OptiNav Array 48 beamforming system.

\section{Nomenclature}

$\theta \quad$ polar angle from the downstream jet direction

$d \quad$ jet nozzle diameter

OB preferred octave band

CF center frequency

CSM cross spectral matrix

CCM cross correlation matrix

PSF array point spread function

\section{Beamforming Methods}

Classical beamforming has been used for a number of years (Ref. 21). Quantitative spectra can be derived by integrating the beamform map and dividing by a normalization factor that is computed by integrating the point spread function (Ref. 22). This procedure is error prone because it depends on a correct sidelobe threshold and an accurate model of the PSF. A number of deconvolution methods have been employed in an attempt to remove the effect of the PSF in order to improve the resolution and the dynamic range and also to simplify the integration process (Ref. 23). Most of these depend heavily on the PSF and are limited to incoherent source distributions. CLEAN-SC (Ref. 24) is a new algorithm that removes both of these restrictions by iteratively subtracting rank-1 models of individual sources from the CSM. The models are constructed so as to represent a given source and all of the energy that is coherent with it. This captures a source and all of its sidelobes, even if the sidelobes are not well characterized by the estimate of the PSF. CLEAN-SC is a narrowband algorithm that operates in the frequency domain.

A new algorithm, TIDY, has been developed to extend CLEAN-SC to the broadband case. TIDY is philosophically similar to CLEAN-SC, but it works in the time domain using the cross correlation matrix (CCM) instead of the frequency domain with CSM. Beamforming with the CCM has been described previously (Ref. 25). In addition to the basic deconvolution function, TIDY incorporates an enhanced resolution mode that weights the CCM elements according to the separation of the microphones and a nonuniform internal beamforming grid that optimizes the allocation of grid points.

TIDY is one module in the OptiNav code Beamform Interactive. This code handles integration of images (video and still) with the beamforming results, displays array spectra and time histories and enables the user to select a subset of each by adjusting sliders. It automatically computes integrated 
spectra, time histories, or depth-sweeps (using conventional beamforming, TIDY, or DAMAS2 (Ref. 26)) for any selected region of interest in the displayed image. Beamform Interactive is over 5000 lines of Java code, not counting standard packages or the ImageJ environment that it runs inside. The mathematics of TIDY will be more fully described in subsequent publications.

\section{Test Setup and Conditions}

\section{Test Hardware}

The test was conducted using the Small Hot Jet Acoustic Rig (SHJAR) in the AAPL at the NASA Glenn Research Center. Several 2 in. nozzles from the SMC series (Ref. 27) were used. NASA Glenn's OptiNav Array 48 beamforming system was positioned $2 \mathrm{~m}$ from a focus point located ten nozzle diameters downstream from the exit (Fig. 1). Array 48 includes 48 Earthworks M30 microphones flush mounted in very flat ( 0.03 in. tolerance) Aluminum tooling plate. The array pattern was designed for operation over $300 \mathrm{~Hz}$ to $48 \mathrm{kHz}$, and has an aperture of $0.93 \mathrm{~m}$ (Fig. 2). Tests were conducted with the array positioned at several angles relative to the jet axis. This paper presents results from the $90^{\circ}$ and $40^{\circ}$ positions (Figs. 3 and 4). In addition, one set of results is given for a modified $90^{\circ}$ position in which the array was translated upstream to relocate the aim point at the nozzle exit. As the figures indicate, the array was rotated at the $40^{\circ}$ position to remain perpendicular to the line between the array center and the aim point. This rotation increases the effective aperture in the flow direction relative to the simpler installation of only translating the array. The beamform maps were still computed on a plane containing the jet and referenced to photographs taken from the $90^{\circ}$ position. For each run, data were acquired for $60 \mathrm{sec}$ using the 24-bit, 96,000 sample/sec audio interface in Array 48 (MOTU 24I/O).

The test setup is quite parallel to the mirror test described in Reference 20. For example, Figure 1(b) resembles a less-detailed version of Figure 2 in the reference. This is interesting because the reference was not discovered and consulted until the final preparation of this paper.

a)

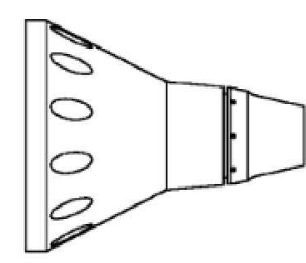

b) 2 in. nozzle 20 in. aim point

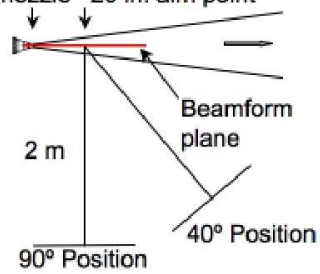

Figure 1.-(a) SMC000 Nozzle. (b) Array positions.

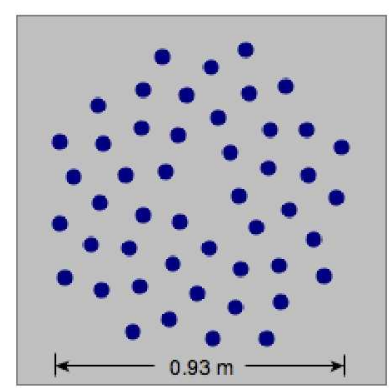

Figure 2.-Array 48.

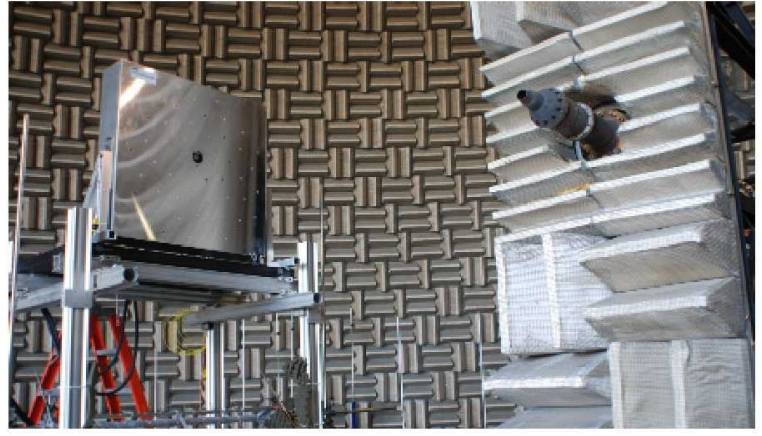

Figure $3 .-90^{\circ}$ array position.

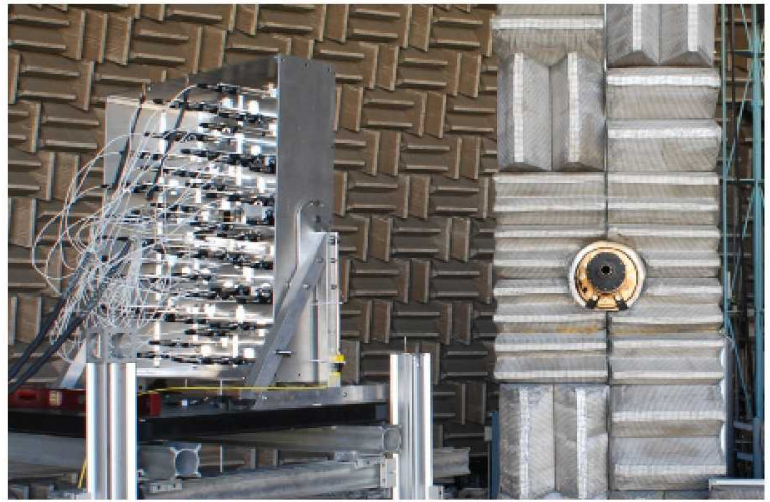

Figure $4 .-40^{\circ}$ array position. 


\section{Test Conditions}

Table 1 presents the nozzle and flow conditions selected for this analysis. The corresponding figures and tables in the Results section are noted for reference. The flow parameters in Table 1 are the ideally expanded jet velocity, $\mathrm{U}_{\mathrm{id}}$, the static temperature ratio, $\mathrm{T}_{\mathrm{s}} / \mathrm{T}_{\mathrm{amb}}$, the jet Mach number $\mathrm{U}_{\mathrm{id}} / a_{j}$, and the acoustic Mach number, $\mathrm{U}_{\mathrm{id}} / a$. The ambient speed of sound, $a$, was computed assuming a nominal temperature of $18.3^{\circ} \mathrm{C}$ in the AAPL, and the jet speed of sound, $a_{j}$, was taken as the product of $a$ and the square root of the static temperature ratio. SMC000 is a round convergent nozzle that serves as the baseline for most SHJAR tests. SMC001 is a chevron nozzle with 6 chevrons of length $22.6 \mathrm{~mm}$ turned in at an angle of $5^{\circ}$. The chevron penetration depth is $0.985 \mathrm{~mm}$ and the effective nozzle diameter is $52.2 \mathrm{~mm}$ (Ref. 28). SMC014 and SMC018 are convergent-divergent nozzles that are designed to be ideally expanded at specific setpoints. The conditions for analysis were chosen from the larger test matrix to investigate the effects of acoustic Mach number (Conds. 1 and 2), chevrons (Conds. 2 and 3), and jet Mach number (Conds. 4 and 5) on the imaged acoustic source distributions.

TABLE 1. - CONDITIONS FOR ANALYSIS

\begin{tabular}{|c|c|c|c|c|c|c|c|c|c|c|c|c|}
\hline \multirow[b]{2}{*}{ Cnd. } & \multirow[b]{2}{*}{ Nozzle } & \multirow[b]{2}{*}{ Description } & \multirow{2}{*}{$\begin{array}{c}\text { Set } \\
\text { Point }\end{array}$} & \multirow{2}{*}{$\begin{array}{c}\text { Uid } \\
(\mathrm{m} / \mathrm{s})\end{array}$} & \multirow{2}{*}{$\begin{array}{c}\text { Ts/ } \\
\text { Tamb }\end{array}$} & \multirow[b]{2}{*}{$\mathrm{Mj}$} & \multirow[b]{2}{*}{$\mathrm{Ma}$} & \multicolumn{2}{|c|}{$90 \mathrm{deg}}$. & \multicolumn{2}{|c|}{$40 \mathrm{deg}}$. & \multirow{2}{*}{ 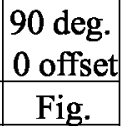 } \\
\hline & & & & & & & & Fig. & Table & Fig. & Table & \\
\hline 1 & SMC000 & Round Conv. & 7 & 299 & 0.84 & 0.95 & 0.87 & 13 & 2 & 14 & 3 & \\
\hline 2 & SMC000 & Round Conv. & 49 & 500 & 2.70 & 0.89 & 1.46 & 15 & 4 & 16 & 5 & \\
\hline 3 & SMC001 & 6 chev., $5^{\circ}$ in. & 49 & 500 & 2.76 & 0.88 & 1.46 & 17 & 6 & & & \\
\hline 4 & SMC014 & Cond.-Div. & 8060 & 618 & 2.37 & 1.17 & 1.81 & 18 & 7 & 19 & 8 & \\
\hline 5 & SMC018 & Cond.-Div. & 12040 & 618 & 1.00 & 1.81 & 1.81 & 20 & 9 & 21 & 10 & \\
\hline 6 & SMC000 & Round Conv. & 9020 & 481 & 1.00 & 1.40 & 1.40 & 22,23 & 11 & 24 & 12 & 25 \\
\hline
\end{tabular}

The two-source theory of jet noise (Refs. 2 and 29) considers noise from fine scale turbulence and noise from large turbulent structures. In this theory, large turbulent structure noise is related to instability waves of the jet. It is the dominant mechanism at the peak radiation angle ( $30^{\circ}$ to $\left.45^{\circ}\right)$ and is usually associated with Mach wave radiation, which requires the source to have a phase velocity greater than the ambient speed of sound. The source region is a portion of the shear layer, beginning near the nozzle and extending as far as $\mathbf{3 0}$ to $\mathbf{3 5}$ diameters downstream. Noise from fine scale turbulence, according to the theory, radiates almost equally in all directions. It is typically the dominant mechanism for angles forward of the peak radiation angle. The source region for noise from fine scale turbulence is held to begin just downstream of the potential core of the jet and is distributed through the mixing region of the jet. The spectral shape of large turbulent structure noise (the F-spectrum) is more sharply peaked than that of noise from fine scale turbulence (the G-spectrum). This means that frequencies far from the peak frequency would tend to favor noise from fine scale turbulence.

Conds. 1 to 5 are expected to be dominated by noise from fine scale turbulence at the $90^{\circ}$ angle, since this angle is far forward of the peak angle for large turbulent structure noise. Their source regions should begin downstream of the potential core, perhaps 4 to 6 diameters from the nozzle, and be distributed in the radial and axial directions. Conds. 1 to 5 should exhibit large turbulent structure noise at $40^{\circ}$.

The underexpanded, supersonic jet in Cond. 6 contains a pattern of shock diamonds. This should provide screech and broadband shock associated noise. The results for Cond. 5 also show evidence of shocks from slight, inadvertent off-design operation. 


\section{Beamforming Results From Simulated Data}

Phased array results from simple, compact, sources usually correspond closely with the simulated point spread function. Since a jet is an extended source, it is important to build intuition by applying beamforming algorithms to simulated data. In a variation on the approach presented by Michel (Ref. 19), the jet is modeled as a line source with a convection velocity and a coherence length. Simulated phased array data is generated in the time domain as follows:

1. Postulate a jet source interval. In the example, it extends from 1 to 11 diameters downstream from the nozzle.

2. Divide the interval into a large number of grid points (example: 401).

3. Use a Gaussian random number generator to produce an independent, white noise time history signal for each grid point at the sampling rate of the data acquisition system $(96 \mathrm{kHz})$.

4. Select a spatial correlation length (example: 2 nozzle diameters).

5. Apply a low pass filter in the spatial direction for each time sample. The cutoff spatial frequency of the filter is the reciprocal of the correlation length. For the example, a 4th order Butterworth filter was used. This has flat spectral response over most of the pass band; is not peaked at low frequency as, for example, a Gaussian or an exponential model would be. This choice was made for convenience.

6. Choose a turbulence convection speed (example: Mach 1.4).

7. Delay the signal for each grid point by the convection time from the start of source region.

8. Compute the spherical distance and the acoustic propagation time from each grid point to each array microphone. Simulate each array microphone signal by delaying and summing the contributions from the grid points.

9. Process the resulting synthetic phased array data as if it were real data. For a frequency-domain beamforming algorithm, this begins by computing the short time Fourier transform for each microphone and then the array cross spectral matrix.

The white noise generated in step 3 does not represent the spectral shape of jet noise. If necessary, a temporal low pass filter could be applied to shape the spectrum. Similarly, the spatial filter in step 5 could be replaced with a model derived from two point turbulence measurements to improve the fidelity of the simulation.

To evaluate the choices of parameter values, the process was first applied to a $180^{\circ}$ polar arc of synthetic microphones ( $5^{\circ}$ interval) instead of the phased array. The arc has a radius of $2 \mathrm{~m}$ and is centered at the array aim point, 10 diameters downstream from the nozzle. The results are shown in Figure 5. Figure 5(a) gives a short segment of the synthetic time history at each arc microphone. There is a region of intense variation with time and angle in the range of $40^{\circ}$ to $50^{\circ}$. This is consistent with a moving, wavy wall radiation model that would give a Mach angle of $\operatorname{arcos}(1 / 1.4)=44.4^{\circ}$. For larger angles, outside of the Mach cone, there is little high frequency content. In the portion of the arc downstream of the peak angle, $\theta<40^{\circ}$, the signals are strong, but appear to be independent of the angle. This can be interpreted as the wavefronts striking that portion of the polar arc array from a direction perpendicular to the array. Similarly the large slope of the wavefronts in Figure 5(a) for $\theta>70^{\circ}$ results from the alignment of the wavefronts parallel to the arc in the upstream region. This portion of the wave is propagating along the polar arc toward the source region, away from the microphones. This unfavorable arrangement produces the low amplitude signal at the microphones.

The polar arc array microphone spectra are given in Figure 5(b). Individual spectra for the $40^{\circ}$ and $45^{\circ}$ microphones are given in Figure 6 . The nearly flat spectral shape within the main lobe is determined by the white noise source mode combined with the effects of the spatial filtering and convection model.

Turning to the phased array, the approximate regions of the arc subtended by the array at the $40^{\circ}$ and $90^{\circ}$ locations are indicated by the green lines in Figure 5(b). (It subtends about $26^{\circ}$ at the $2 \mathrm{~m}$ radius.) At the $40^{\circ}$ position, the array is in the main lobe of the simulated jet directivity pattern for the entire frequency range. In the $90^{\circ}$ case, there is a dramatic falloff in level for frequencies above about $12 \mathrm{kHz}$. 

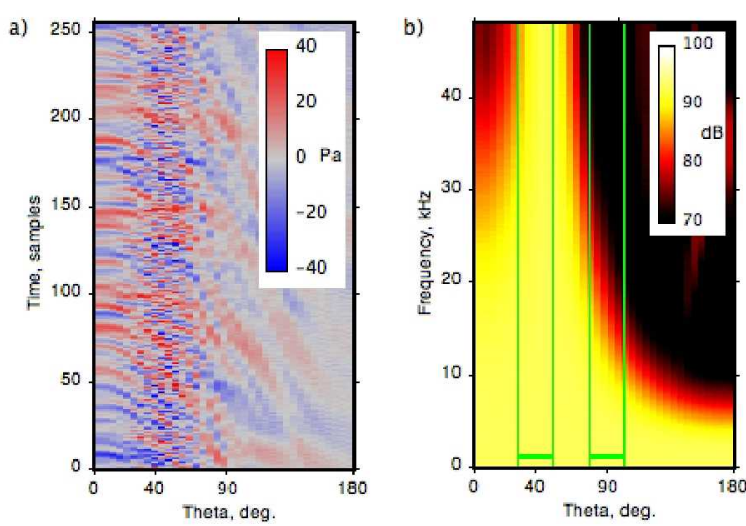

Figure 5.-Jet simulation evaluated at a polar array.

(a) Time history, (b) Spectra. The approximate extent of the array is shown by the green lines in (b).

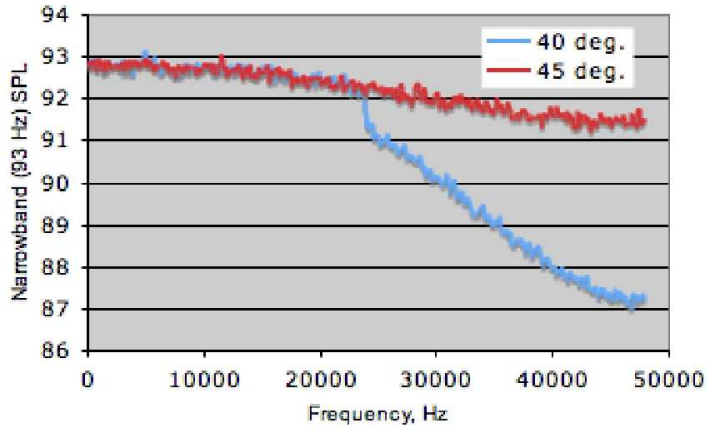

Figure 6.-Spectra from simulated jet.

The $40^{\circ}$ array position is considered first. Applying the simulation process for the array itself and then performing conventional beamforming with diagonal deletion gives the octave band beamform maps shown in Figure 7. (Conventional beamforming in the frequency domain cannot be applied to a whole octave in one operation; a number of subbands need to be combined.) The highest frequency band, the $32 \mathrm{kHz}$ OB, shows the source region nicely. For successively lower bands, the apparent source extent becomes extended in the radial and then the axial directions. This is a simple array resolution effect. Within the main directivity lobe, the source extent, motion, and coherence do not interfere with the beamforming in this case. Integrating the beamform maps and correcting for the array point spread function produces the array-average levels (not shown), as expected.

The $1 / 12 \mathrm{OB}$ array-average microphone spectrum is shown at the top of Figure 8 . This spectrum is not a result of beamforming; is it simply the energy average of the autospectra of the 48 microphones. The upward slope in this case results from the nearly-white source spectrum combined with the proportional nature of the $1 / 12$ OBs.

Conventional beamforming with diagonal deletion at $90^{\circ}$ is shown in Figure 9. The lowest three OB results are similar to the $40^{\circ}$ case (Fig. 7). As predicted from Figure 5, the beamforming levels drop off relative to $40^{\circ}$ as the frequency increases. For the highest two bands, the source appears biased toward the nozzle. This occurs because upstream end of the jet is farther from the array and radiation from this part of the source to the array has a shallower angle; closer to the Mach cone. The bright spots at the ends of the simulated jet in the $32 \mathrm{kHz}$ OB are believed to be diffraction effects resulting from the abrupt termination of the source. Apart from the highest frequencies where the array is in a deep directivity null, conventional beamforming is still successful outside the Mach cone.

Figure 10 shows that effect of including the diagonal elements of the CSM in the $90^{\circ}$ case. The artifacts are also seen in processing the real jet noise data without diagonal deletion. This provides and additional case, in addition to self noise from grazing flow, in which diagonal deletion is important for successful beamforming.

The effect of TIDY in the $90^{\circ}$ simulation is shown in Figure 11. As before, TIDY considerably sharpens the results. It does not recover the energy at high frequency; this sound does not propagate to the array. The Mach cone effect on the array average spectrum can be seen by comparing the $1 / 12$ OB spectra between Figures 8 and 11 . 


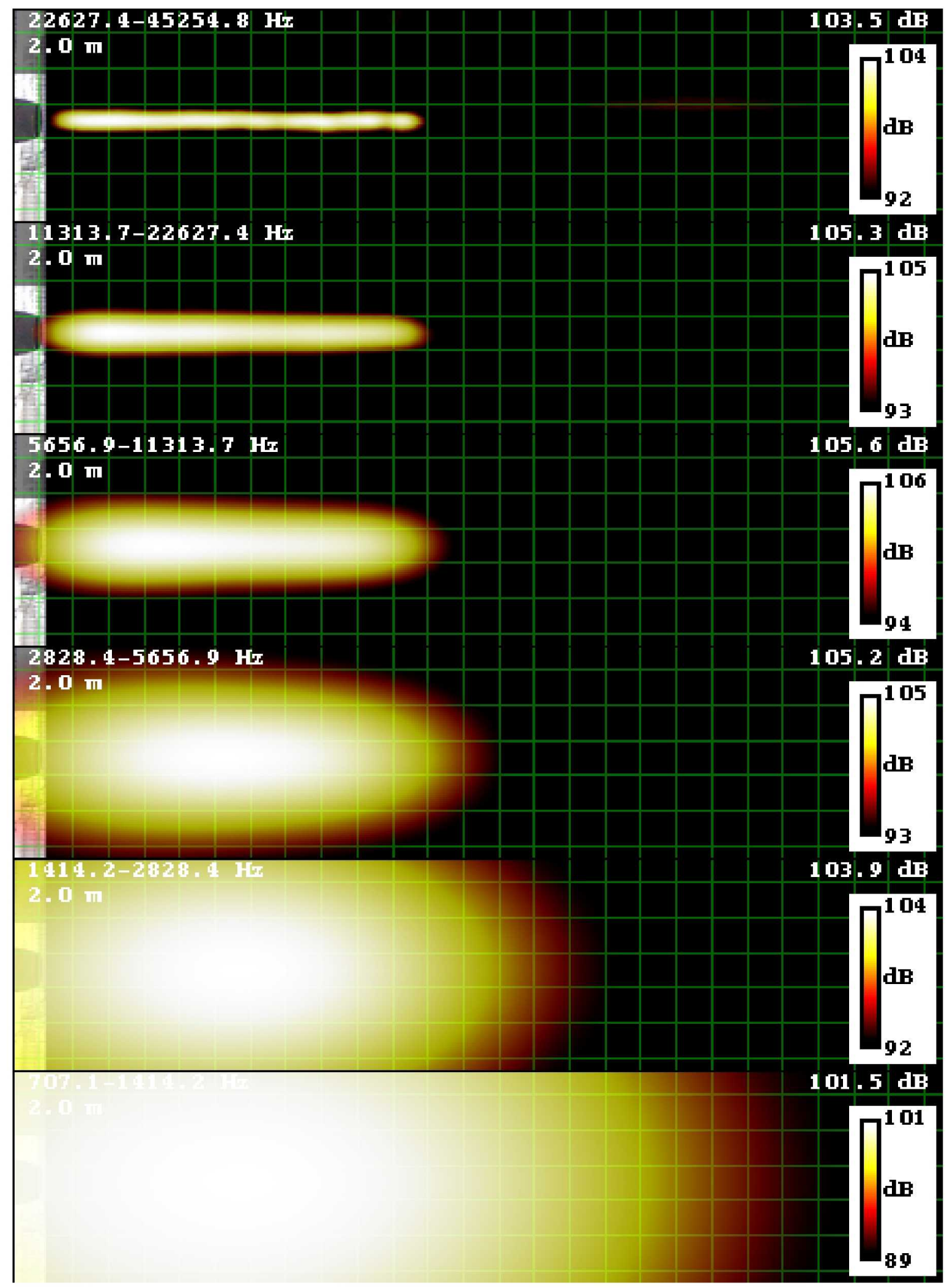

Figure 7.-Conventional beamforming for simulated jet; $40^{\circ}$ array position. 


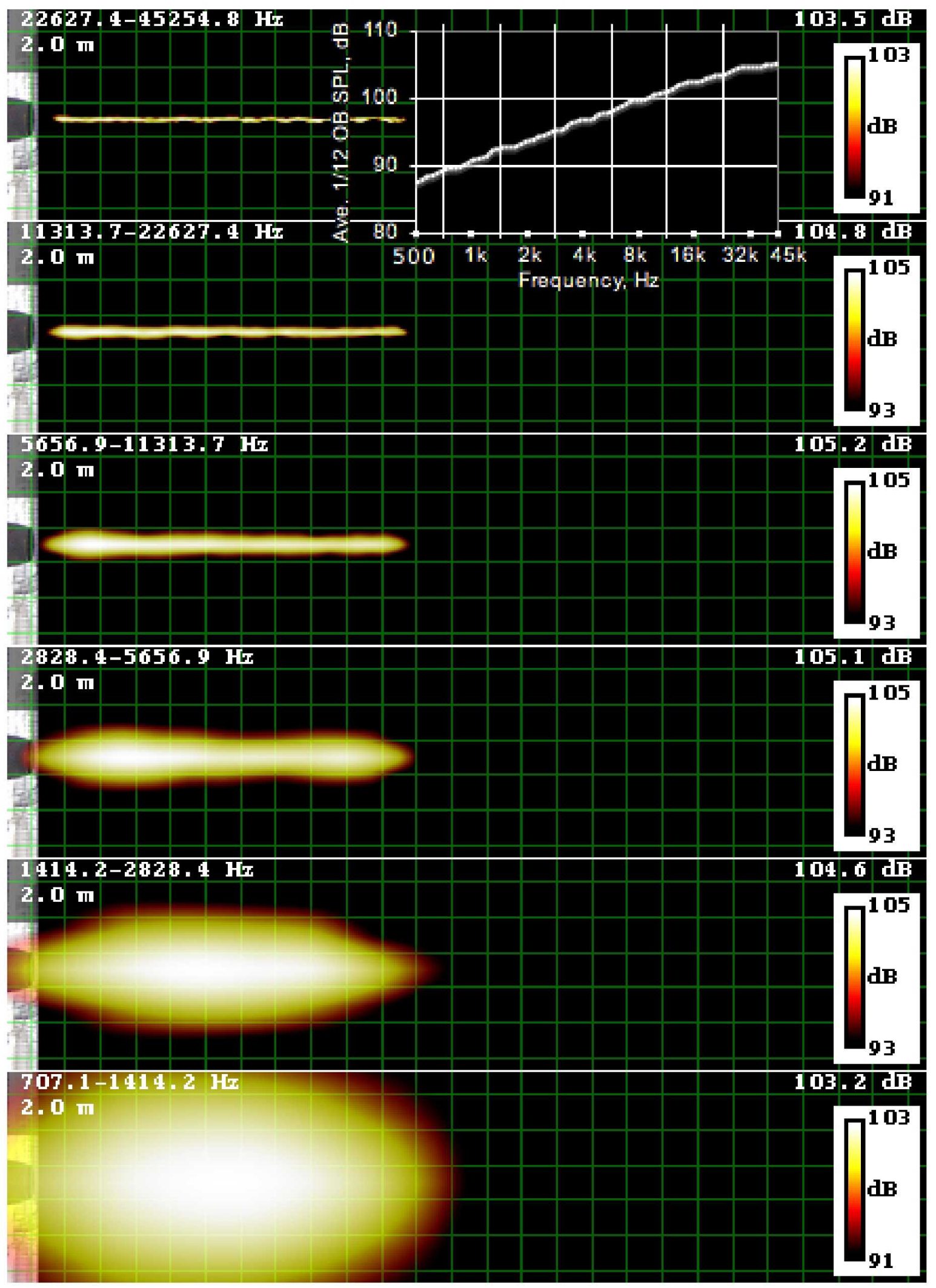

Figure 8.-TIDY beamforming for simulated jet; $40^{\circ}$ array position. 


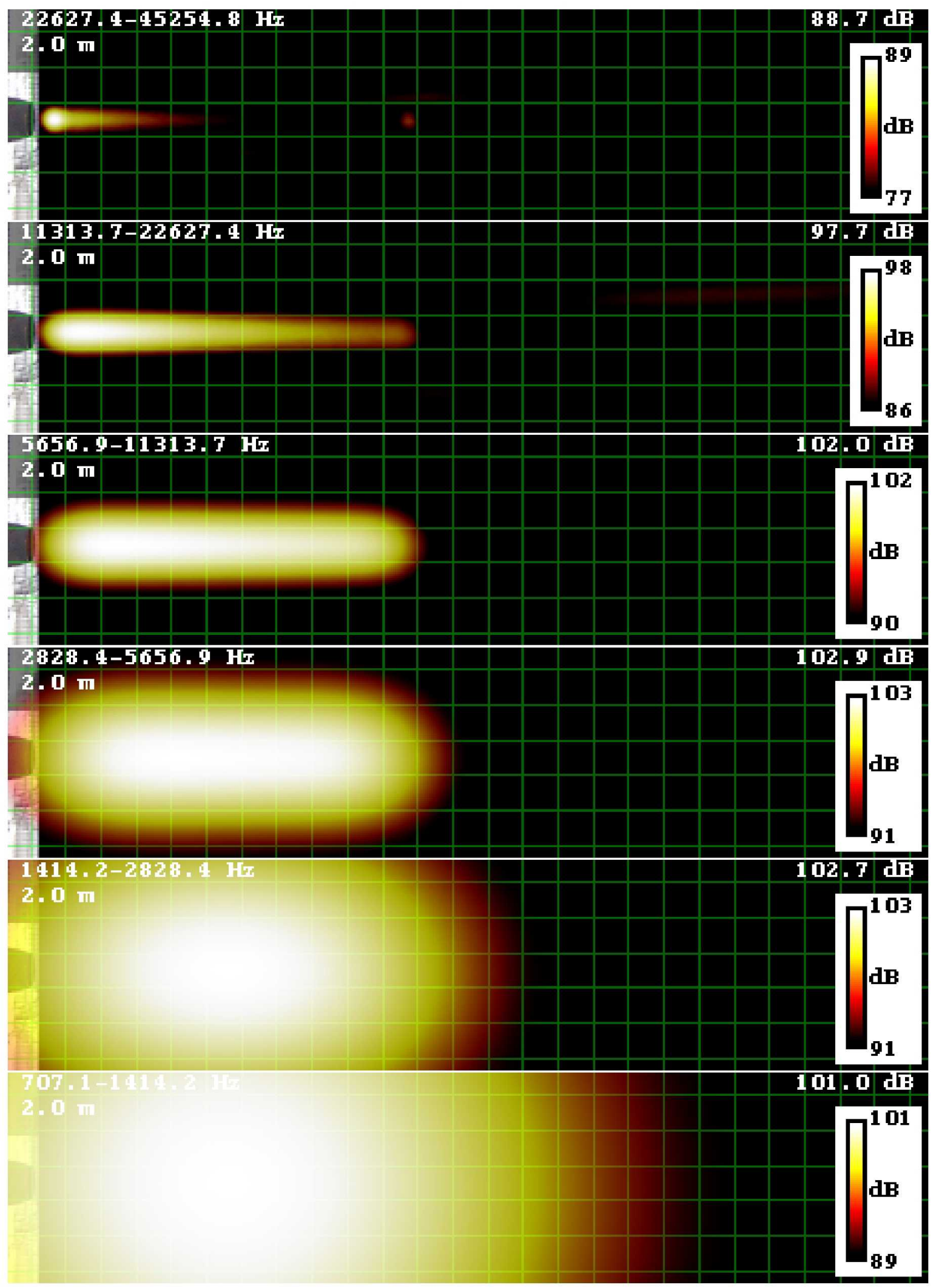

Figure 9.-Conventional beamforming for simulated jet; $90^{\circ}$ array position. 


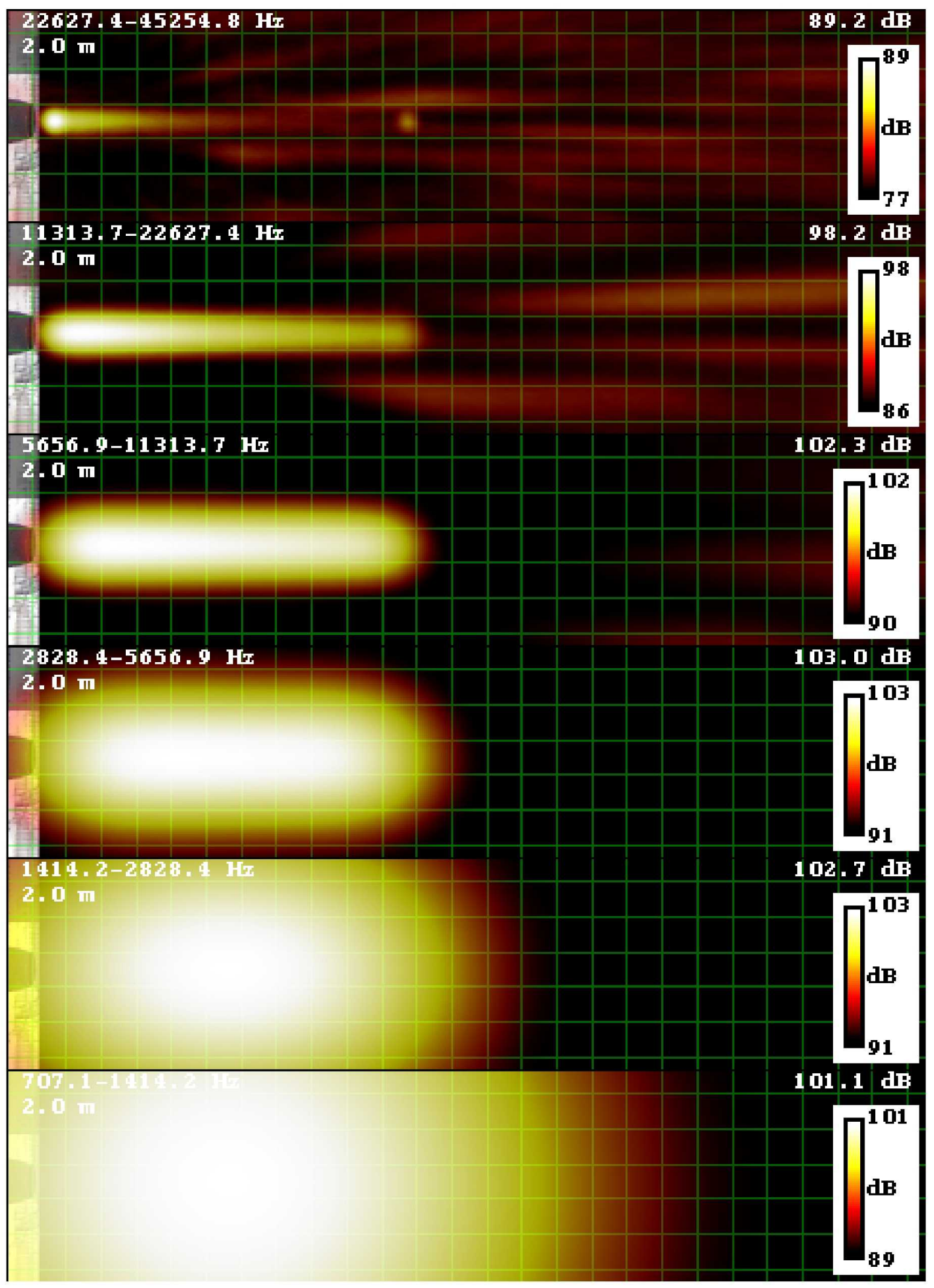

Figure 10.-Conventional beamforming for simulated jet; $90^{\circ}$ array position. No diagonal deletion. 


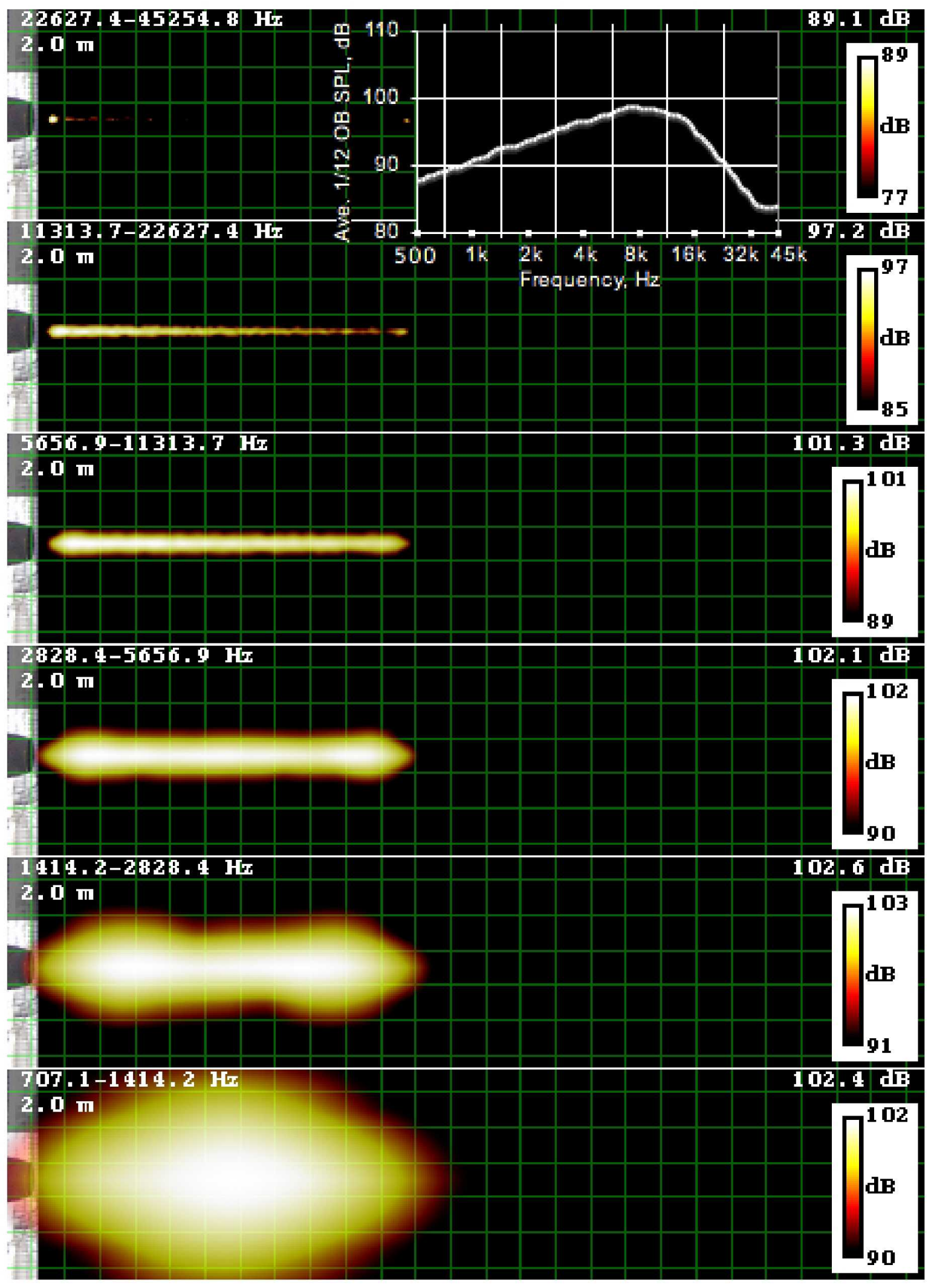

Figure 11.-TIDY beamforming for simulated jet; $90^{\circ}$ array position. 


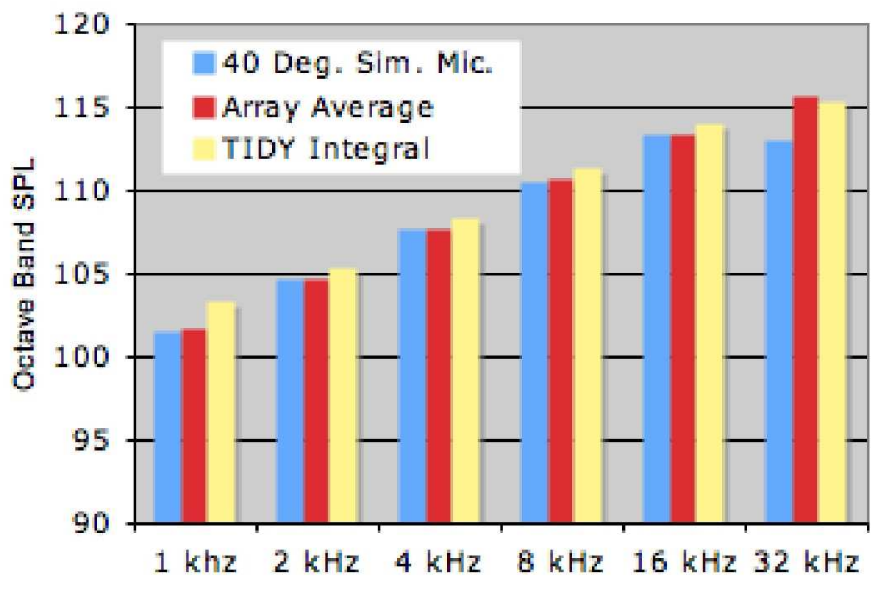

Figure 12.-Octave band levels for simulated jet.

The TIDY beamforming software automatically outputs the integrated results for the beamform map along with the spectral and microphone average of the array data. These results, along with the OB results for the $40^{\circ}$ individual microphone are shown in Figure 12. The agreement is within a $\mathrm{dB}$ or so for most of the bands. This validates a key goal of the array: the ability to reproduce individual microphone levels for a complex source.

Applying Equation (2) to this example with the array aperture of $0.93 \mathrm{~m}, R=2 \mathrm{~m}$, and $\Lambda=4 \mathrm{in}$. $(0.1016 \mathrm{~m})$, the upper limit of frequency to satisfy Equation (2) is $17.8 \mathrm{kHz}$. Figure 12 shows no sign of trouble in the $16 \mathrm{kHz}$ OB, with an upper limit of $22.6 \mathrm{kHz}$. The disagreement between $40^{\circ}$ microphone and the array average in the $32 \mathrm{kHz}$ OB can be taken as effect of Equation (2). The extended source has directivity variation over the array. (This was seen in Fig. 5(b) as well.) The beamforming result still has good agreement with the array average. This is the reason for characterizing Equation (2) as conservative.

\section{Results}

Results from jet rig test Conds. 1 to 6 are presented in Figures 13 to 25 and Tables 2 to 12 . The six octave bands used for the analysis are specified by the band limits in the figures and the geometric center frequencies (CF) in the tables.

\section{Subsonic Cold Jet}

Figures 13 and 14 show the TIDY beamforming results for Cond. 1 from the $90^{\circ}$ and $40^{\circ}$ positions. In each of the OBs, the beamforming levels are higher at the downstream position, presumably due to Doppler amplification. The source distributions are similar at the two angles for the lower bands: 1, 2, and $4 \mathrm{kHz}$. Starting with the $8 \mathrm{kHz}$ OB, the images differ between the two observation angles. The $90^{\circ}$ results show extended sources at the shear layer, starting just downstream of the nozzle, at high frequency. This is the region of the jet that is supposed to indicate large scale structure noise according to the two source theory. As noted in References 2, 30, and 31, it is possible for large scale structure noise to be generated by subsonic sources if they are spatially nonuniform. However, the case of the $90^{\circ}$ angle, especially at high frequency should be dominated by noise from fine scale turbulence. 


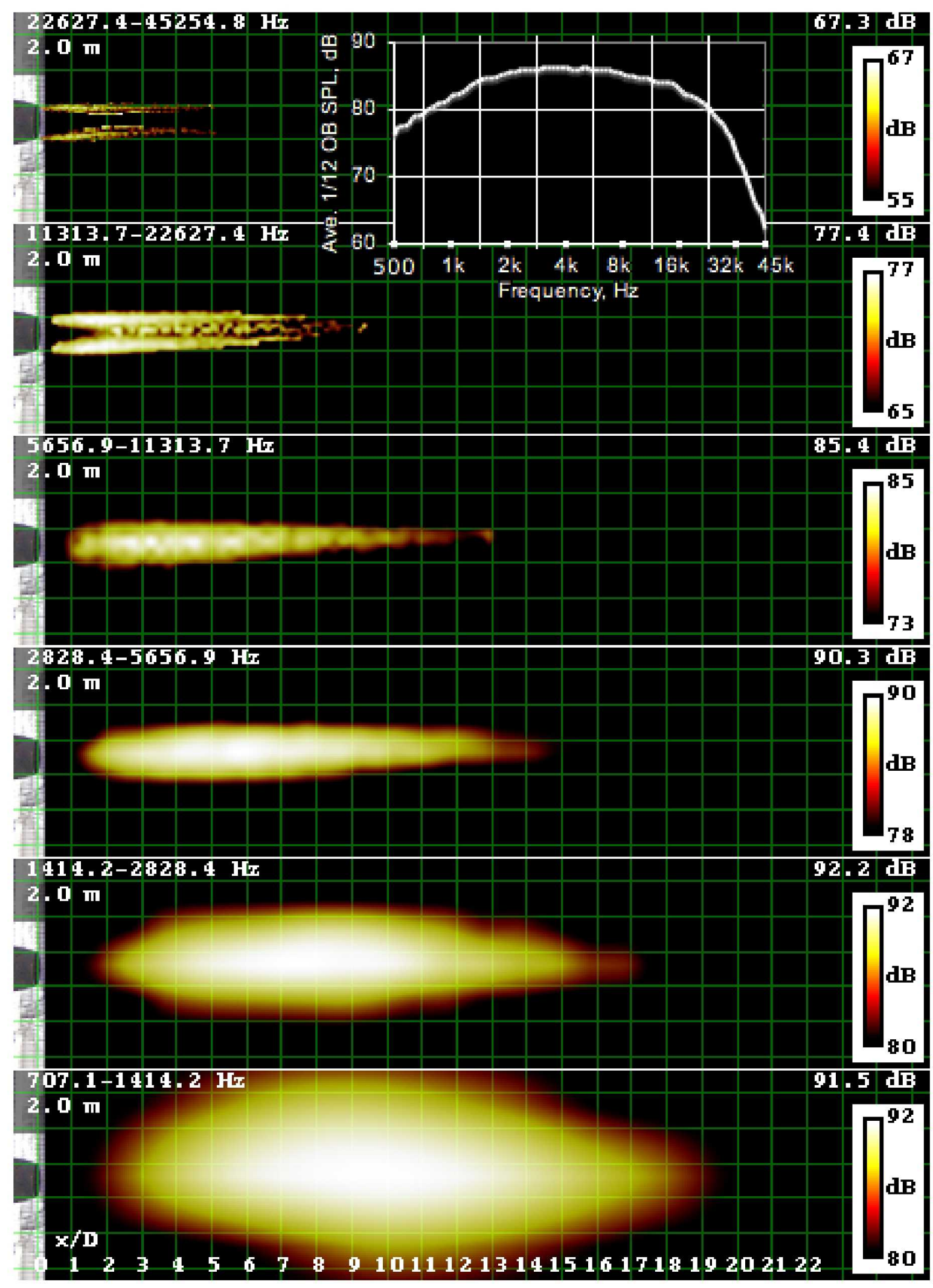

Figure 13.-Condition $1,90^{\circ}$. 


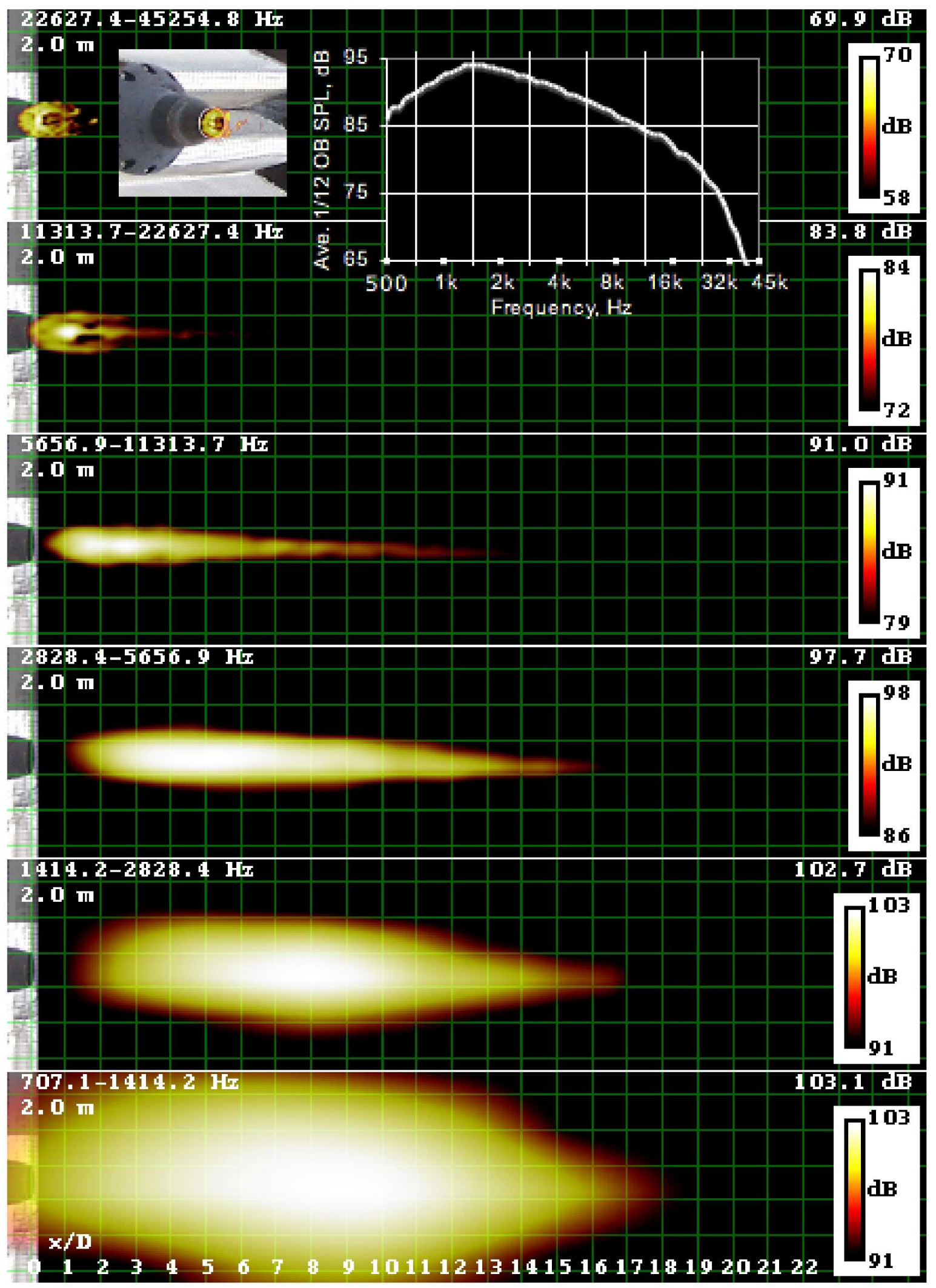

Figure 14.-Condition $1,40^{\circ}$. The inset represents a beamforming plane parallel to the array. 


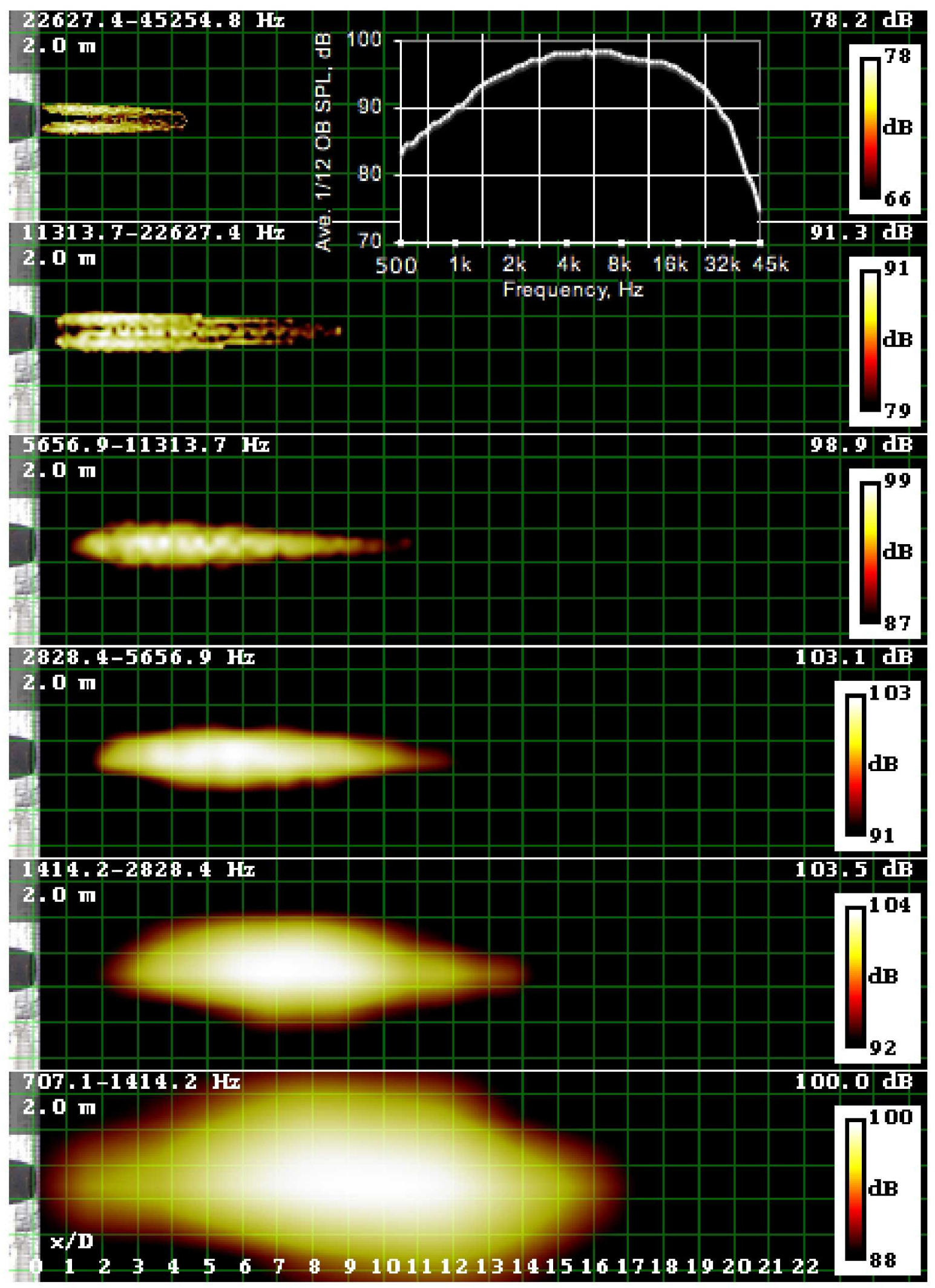

Figure 15.-Condition 2, $90^{\circ}$. 


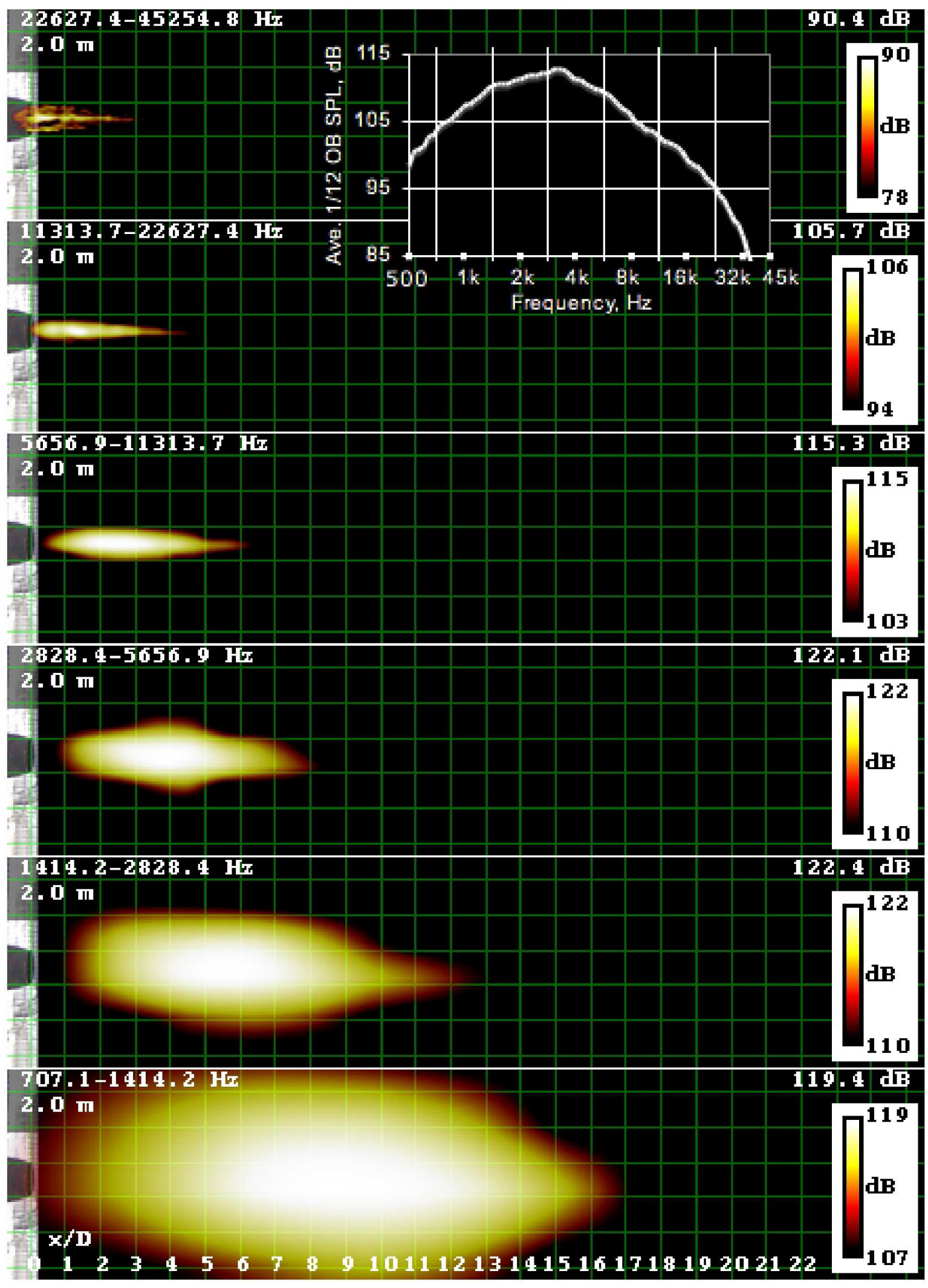

Figure 16.-Condition $2,40^{\circ}$. 


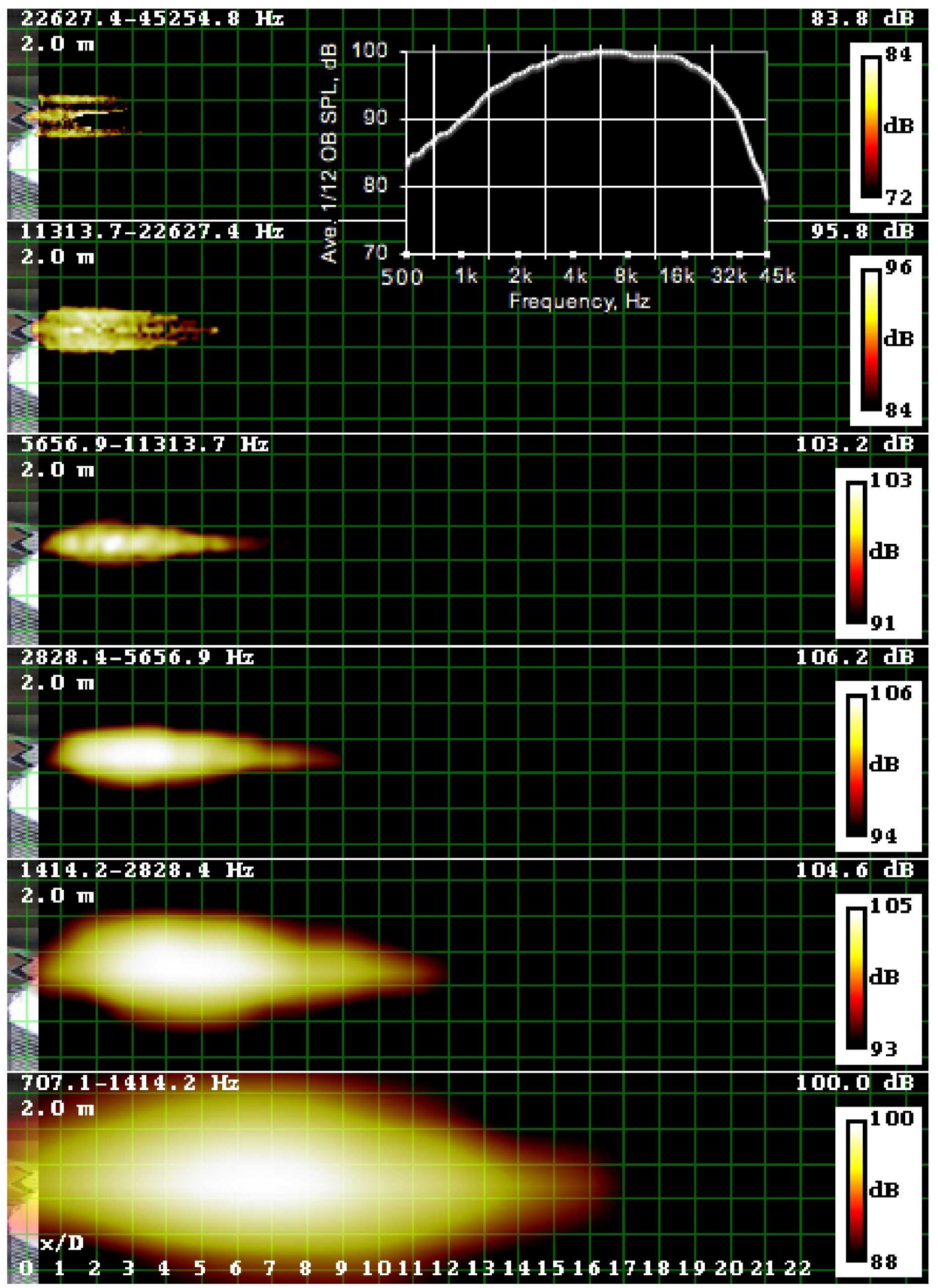

Figure 17.-Condition $3,90^{\circ}$. 


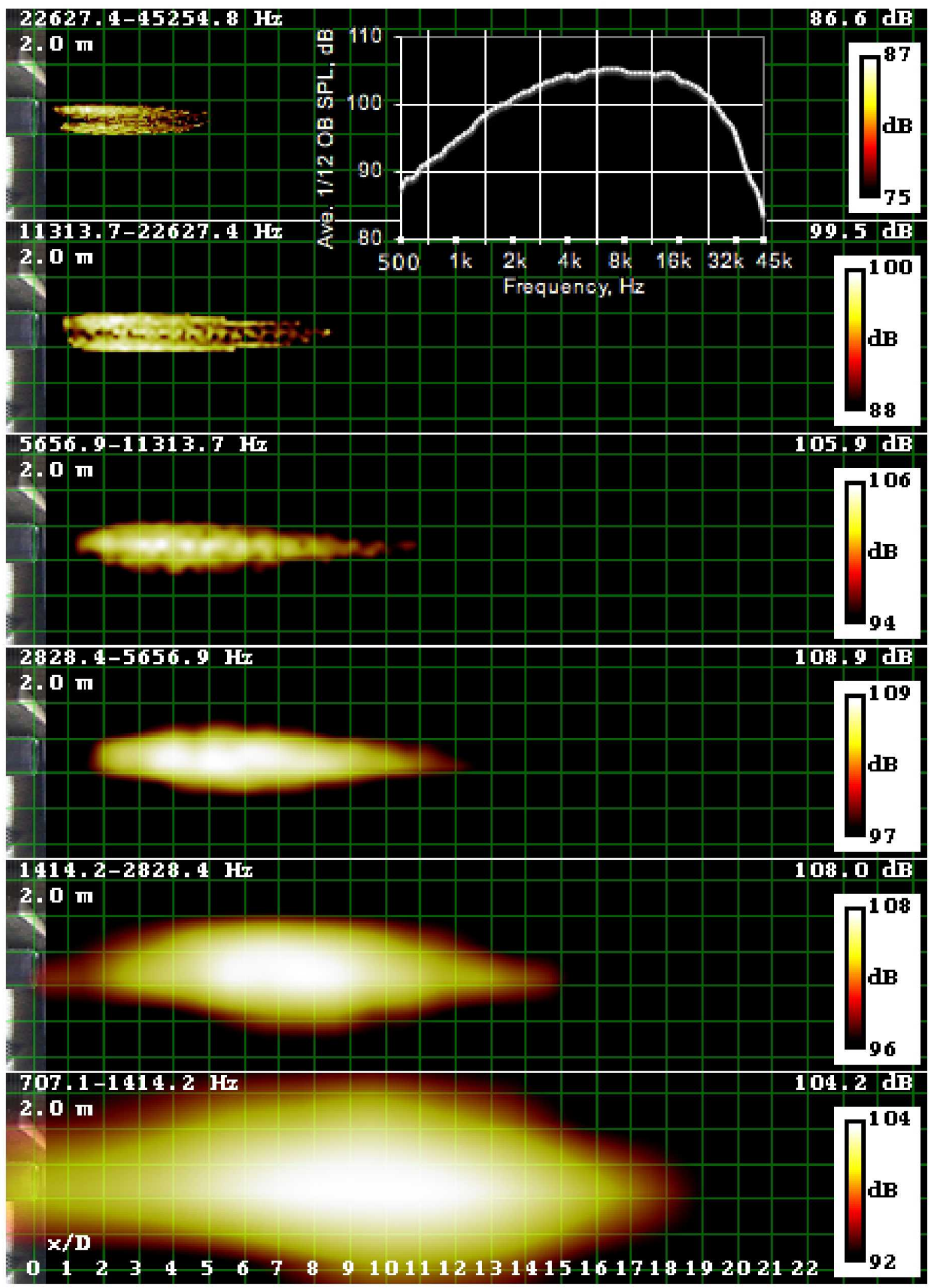

Figure 18.-Condition $4,90^{\circ}$. 


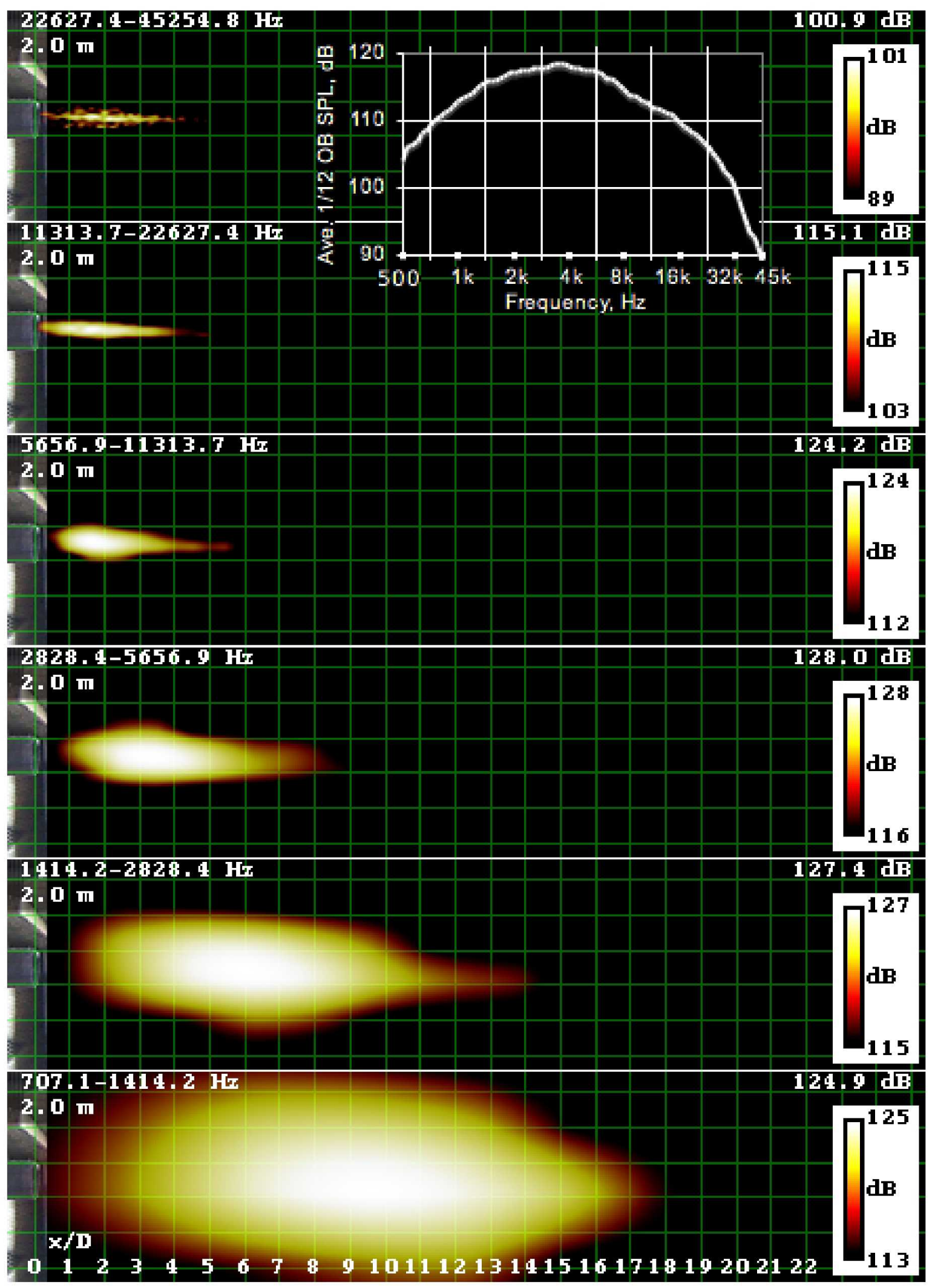

Figure 19.-Condition $4,40^{\circ}$. 


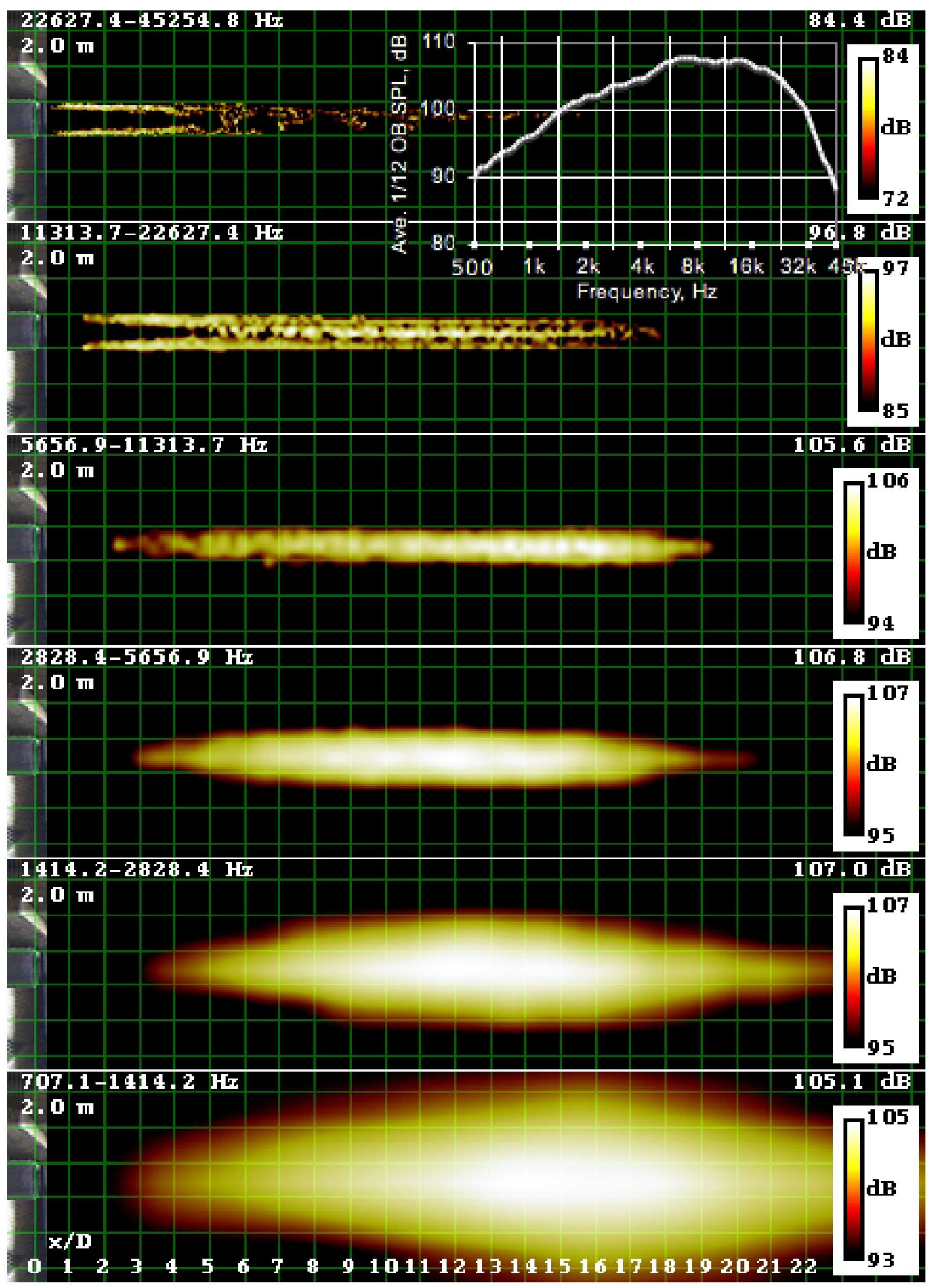

Figure 20.-Condition 5, $90^{\circ}$. 


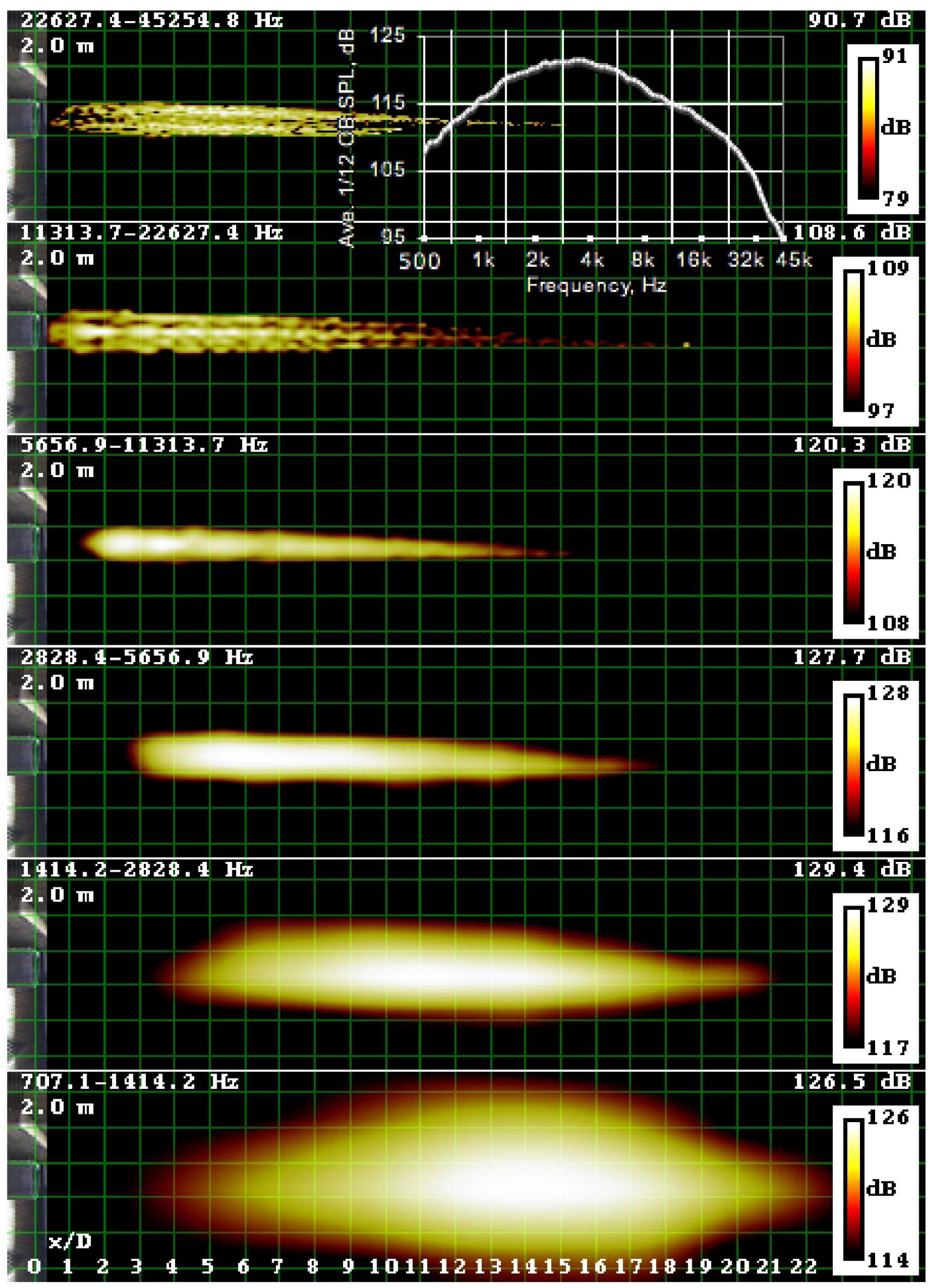

Figure 21.-Condition $5,40^{\circ}$. 


\begin{tabular}{rrrrr}
\multicolumn{5}{c}{ TABLE 2.CONDITION 1 AT 90 } \\
CF (kHz) & BF Peak (dB) & Array Ave. (dB) & TIDY Integ. (dB) & Source Loc (diam.) \\
1 & 91.5 & 92.9 & 93.0 & 9.4 \\
2 & 92.2 & 96.3 & 95.5 & 7.2 \\
4 & 90.3 & 96.9 & 95.9 & 5.4 \\
8 & 85.4 & 96.1 & 94.2 & 3.0 \\
16 & 77.4 & 93.7 & 91.0 & 1.3 \\
32 & 67.3 & 86.0 & 79.3 & 2.2 \\
OASPL & & 102.5 & 101.3 &
\end{tabular}

TABLE 3.-CONDITION 1 AT $40^{\circ}$

$\begin{array}{rrrrr}\text { CF (kHz) } & \text { BF Peak (dB) } & \text { Array Ave. (dB) } & \text { TIDY Integ. (dB) } & \text { Source Loc (diam.) } \\ 1 & 103.1 & 102.8 & 103.9 & 8.6 \\ 2 & 102.7 & 104.0 & 104.1 & 7.7 \\ 4 & 97.7 & 101.5 & 101.0 & 4.9 \\ 8 & 91.0 & 97.8 & 95.6 & 2.5 \\ 16 & 83.8 & 92.7 & 88.8 & 0.8 \\ 32 & 69.9 & 83.3 & 77.5 & 0.0 \\ \text { OASPL } & & 108.2 & 108.3 & \end{array}$

TABLE 4.-CONDITION 2 AT $90^{\circ}$

$\begin{array}{rrrrr}\text { CF (kHz) } & \text { BF Peak (dB) } & \text { Array Ave. (dB) } & \text { TIDY Integ. (dB) } & \text { Source Loc (diam.) } \\ 1 & 100.0 & 101.1 & 101.4 & 9.2 \\ 2 & 103.5 & 106.1 & 105.6 & 6.6 \\ 4 & 103.1 & 108.3 & 107.5 & 5.4 \\ 8 & 98.9 & 108.0 & 106.8 & 3.5 \\ 16 & 91.3 & 106.0 & 104.2 & 1.8 \\ 32 & 78.2 & 98.3 & 92.7 & 0.8 \\ \text { OASPL } & & 113.6 & 112.6 & \end{array}$

TABLE 5.-CONDITION 2 AT $40^{\circ}$

$\begin{array}{rrrrr}\text { CF (kHz) } & \text { BF Peak (dB) } & \text { Array Ave. (dB) } & \text { TIDY Integ. (dB) } & \text { Source Loc (diam.) } \\ 1 & 119.4 & 118.5 & 119.9 & 8.4 \\ 2 & 122.4 & 122.3 & 122.8 & 5.3 \\ 4 & 122.1 & 122.5 & 122.7 & 3.6 \\ 8 & 115.3 & 117.5 & 117.0 & 2.2 \\ 16 & 105.7 & 110.9 & 109.0 & 1.1 \\ 32 & 90.4 & 100.7 & 97.2 & 0.1 \\ \text { OASPL } & & 126.9 & 127.3 & \end{array}$




\begin{tabular}{rrrrr}
\multicolumn{5}{c}{ TABLE 6.CONDITION 3 AT 90 } \\
CF (kHz) & BF Peak (dB) & Array Ave. (dB) & TIDY Integ. (dB) & Source Loc (diam.) \\
1 & 100.0 & 101.2 & 101.7 & 6.3 \\
2 & 104.6 & 106.9 & 106.6 & 4.0 \\
4 & 106.2 & 109.7 & 109.1 & 3.3 \\
8 & 103.2 & 110.0 & 108.8 & 2.0 \\
16 & 95.8 & 108.8 & 107.0 & 1.1 \\
32 & 83.8 & 101.8 & 96.2 & 1.1 \\
OASPL & & 115.4 & 114.3 &
\end{tabular}

TABLE 7.-CONDITION 4 AT $90^{\circ}$

$\begin{array}{rrrrr}\text { CF (kHz) } & \text { BF Peak (dB) } & \text { Array Ave. (dB) } & \text { TIDY Integ. (dB) } & \text { Source Loc (diam.) } \\ 1 & 104.2 & 105.8 & 106.2 & 10.1 \\ 2 & 108.0 & 111.1 & 110.7 & 7.5 \\ 4 & 108.9 & 114.5 & 113.7 & 5.0 \\ 8 & 105.9 & 115.1 & 113.9 & 3.5 \\ 16 & 99.5 & 114.0 & 112.0 & 2.2 \\ 32 & 86.6 & 106.8 & 100.6 & 1.4 \\ \text { OASPL } & & 120.3 & 119.1 & \end{array}$

TABLE 8. - CONDITION 4 AT $40^{\circ}$

$\begin{array}{rrrrr}\text { CF (kHz) } & \text { BF Peak (dB) } & \text { Array Ave. (dB) } & \text { TIDY Integ. (dB) } & \text { Source Loc (diam.) } \\ 1 & 124.9 & 124.1 & 125.5 & 9.4 \\ 2 & 127.4 & 128.0 & 128.1 & 5.9 \\ 4 & 128.0 & 128.9 & 128.9 & 3.1 \\ 8 & 124.2 & 125.7 & 125.1 & 1.5 \\ 16 & 115.1 & 120.4 & 118.6 & 1.4 \\ 32 & 100.9 & 111.7 & 108.1 & 2.0 \\ \text { OASPL } & & 133.3 & 133.4 & \end{array}$

TABLE 9.-CONDITION 5 AT $90^{\circ}$

$\begin{array}{rrrrr}\text { CF (kHz) } & \text { BF Peak (dB) } & \text { Array Ave. (dB) } & \text { TIDY Integ. (dB) } & \text { Source Loc (diam.) } \\ 1 & 105.1 & 107.5 & 107.5 & 13.8 \\ 2 & 107.0 & 112.4 & 111.4 & 11.7 \\ 4 & 106.8 & 115.9 & 114.6 & 11.7 \\ 8 & 105.6 & 118.3 & 116.3 & 14.9 \\ 16 & 96.8 & 117.2 & 112.0 & 10.5 \\ 32 & 84.4 & 110.7 & 99.4 & 1.1 \\ \text { OASPL } & & 122.9 & 120.3 & \end{array}$




\begin{tabular}{rrrrr}
\multicolumn{5}{c}{ TABLE 10.CONDITION 5 AT 40 } \\
CF (kHz) & BF Peak (dB) & Array Ave. (dB) & TIDY Integ. (dB) & Source Loc (diam.) \\
1 & 126.5 & 126.6 & 127.5 & 13.9 \\
2 & 129.4 & 131.4 & 131.7 & 11.0 \\
4 & 127.7 & 131.9 & 131.7 & 5.7 \\
8 & 120.3 & 128.0 & 126.7 & 3.5 \\
16 & 108.6 & 122.9 & 120.7 & 1.7 \\
32 & 90.7 & 114.8 & 107.5 & 5.4 \\
OASPL & & 136.3 & 136.1 &
\end{tabular}

TABLE 11.-CONDITION 6 AT $90^{\circ}$

$\begin{array}{rrrrr}\text { CF (kHz) } & \text { BF Peak (dB) } & \text { Array Ave. (dB) } & \text { TIDY Integ. (dB) } & \text { Source Loc (diam.) } \\ 1 & 104.4 & 105.6 & 105.7 & 10.3 \\ 2 & 108.1 & 111.4 & 110.0 & 7.4 \\ 4 & 113.0 & 115.6 & 116.2 & 6.5 \\ 8 & 113.8 & 120.6 & 119.6 & 6.5 \\ 16 & 101.8 & 117.1 & 114.0 & 7.1 \\ 32 & 87.3 & 109.7 & 100.7 & 7.1 \\ \text { OASPL } & & 123.6 & 122.4 & \end{array}$

TABLE 12.-CONDITION 6 AT $40^{\circ}$

$\begin{array}{rrrrr}\text { CF }(\mathrm{kHz}) & \text { BF Peak (dB) } & \text { Array Ave. (dB) } & \text { TIDY Integ. (dB) } & \text { Source Loc (diam.) } \\ 1 & 124.0 & 123.2 & 124.6 & 10.6 \\ 2 & 126.5 & 127.5 & 127.6 & 8.9 \\ 4 & 122.5 & 124.9 & 125.0 & 6.8 \\ 8 & 115.0 & 120.5 & 119.6 & 3.9 \\ 16 & 107.0 & 116.1 & 112.6 & 1.4 \\ 32 & 92.1 & 107.7 & 102.1 & 1.1 \\ \text { OASPL } & & 130.9 & 131.1 & \end{array}$


It is possible that the mirror measurements used to formulate the two-source model missed this high frequency shear layer sound. The mirror should have a narrow focus point at high frequency, and it was aimed at the jet centerline, between the upper and lower shear layers. Discussion of the elliptic mirror technique in Reference 2 includes the observation that that mirror's resolution in the range direction is not sufficient to focus on the jet centerline to the exclusion of shear layer sources closer to or farther from the mirror. Simulation of the geometry of elliptic mirror test setup using an OptiNav 3D Fraunhofer diffraction program confirmed this. Reference 2 states that the mirror "listens" to an entire axial slice of the jet. This does not mean that the shear layer noise is fully captured when the elliptic mirror is focused only on the centerline. Apart from the application of TIDY (which is not required to illustrate this point), the acoustical principles of Array 48 are similar to the mirror method. Array 48 would not have detected the shear layer noise in the highest band in Figure 13 if it had only been focused on the jet centerline. The portions of the cylindrical shear layer at the tops and the bottoms of the images in Figure 13 are more important than the portions aligned with jet centerline because they contribute more thickness when projected in the direction of the array.

Turning to Figure 14, the high frequency results from the $40^{\circ}$ position show a source on the jet axis near the nozzle $(16 \mathrm{kHz}$ OB) and ring structures at the nozzle. These rings may be direct radiation from the boundary layer inside the nozzle lip. Their elliptical shape is a parallax effect resulting from the oblique beamforming plane. The inset in Figure 14 shows the result of orienting the beamforming plane parallel to the array and focusing at the nozzle for the $32 \mathrm{kHz}$ OB. (This result does depend on TIDY.)

The spectrum in Figure 14 peaks at a lower frequency than the one in Figure 13, and is more sharply peaked. This is qualitatively consistent with the appearance of the F-spectrum at $40^{\circ}$ and the G-spectrum at $90^{\circ}$, as expected in the two source theory.

Tables 2 and 3 give the beamforming peak, the array average, and the TIDY integral sound pressure levels, as well as the $x$ coordinates of the beamforming peaks for Cond. 1 at the $90^{\circ}$ and $40^{\circ}$ positions. The beamforming peak levels are not very meaningful for these distributed sources. The array average and TIDY integrals agree to within a $\mathrm{dB}$ or so except at that $32 \mathrm{kHz} \mathrm{OB}$, validating the beamforming methodology. The peak source locations vary strongly with frequency, and are similar between the two cases, except at the highest frequencies.

\section{Subsonic Hot Jet and Chevrons}

Figures 15 and 16 give the beamforming plots for Cond. 2, which has a flow speed that is less than the speed of sound in the heated jet but greater than the ambient sound speed. The $90^{\circ}$ results appear similar to Cond. 1, except that the shear layer noise at high frequency is more compact in the radial direction. The $40^{\circ}$ plots show that the noise source has moved forward and the levels are considerably higher relative to the $90^{\circ}$ case for Cond. 1 or both angles for Cond. 2. The increased level and forward source location is consistent with the expected increase of large scale structure noise. The increase is on the jet axis, not at the shear layer as expected. Tables 4 and 5 give the summary results. Table 5 documents the level increase and axial source location change.

The effect of the chevron nozzle for the $90^{\circ}$ position can be seen by comparing Figure 17 with Figure 15 and Table 6 with Table 4. The chevron nozzle increases the $90^{\circ}$ noise in all of the bands, with larger changes at higher frequency. The noise source locations have move forward, and the individual vortices from the chevrons can be seen in the $32 \mathrm{kHz}$ band.

\section{Supersonic Matched Jet}

Conds. 4 and 5 have the same flow speed and the same acoustic Mach number, 1.81, but Cond. 4 has a lower jet Mach number because the flow is hot. Results are given in Figures 18 to 21 and Tables 7 to

10. Comparing Figure 18 to Figure 19 shows the same trend seen for Cond. 2: the $40^{\circ}$ plots have higher levels and source locations that are more forward and, at high frequency, located on the jet axis as 
opposed to the shear layer. Cond. 5 has a dramatically extended source region at all frequencies and both observation angles. Shear layer and centerline noise are resolved separately in the $16 \mathrm{kHz} \mathrm{OB}$. The $32 \mathrm{kHz}$ band for Cond. 5 at $90^{\circ}$ shows a complex structure that includes sharply resolved shear layer noise extending from 1 to 4 nozzle diameters, followed by a periodic structure with a spacing of about

one nozzle diameter. Cond. 5 at $40^{\circ}$ also differs significantly from Cond. 4 . In addition to the greater axial extent, it displays shear layer noise in the 16 and $32 \mathrm{kHz}$ OBs that is totally lacking from Cond. 4.

\section{Underexpanded Supersonic Jet}

The underexpanded supersonic jet of Cond. 6 has a strong screech tone at $2812 \mathrm{~Hz}$ with a harmonic at $5624 \mathrm{~Hz}$ (Fig. 22). The $90^{\circ}$ plots for the 16 and $32 \mathrm{kHz}$ OBs show evidence of the shock cell structure, and the lower frequency band also shows shear layer noise extending over 6 to $12 \mathrm{~d}$. The screech tone frequency places it near the top of the $2 \mathrm{kHz}$ OB. The plots for this band show at least three extra sources in addition to the broadband jet noise: one just aft of the nozzle, and two others on the jet axis.

Figure 23 shows TIDY beamforming for the tone using an expanded grid. Five tone spots appear: two in the jet, one at the nozzle lip, one at the pipe flange (Fig. 4), and an additional source mid way along the pipe. The jet spots may be consistent with the standard model for screech. The radiation begins with two (or more) shock cells emitting sound with a phase relationship that creates a beam going upstream. The acoustic wave in the vicinity of the nozzle lip modulates the shear layer at that point. The unstable shear layer amplifies the flow disturbance and the amplified energy reaches the shock cell source regions at the appropriate times to complete the feedback loop for the tone. Extending the standard screech model, the acoustic beam will scatter from objects that it encounters, such as the nozzle, creating apparent sources upstream of the jet. This could account for the upstream spots in Figure 23. The mid-pipe spot is the most problematic, but it may be associated with the nonuniform external pipe structure.

The screech tone is not evident at the beamforming plots for the $40^{\circ}$ position (Fig. 24), although it can be seen in the 1/12 OB array average spectrum. The plots appear similar to Figure 16 (Cond. 2) and Figure 19 (Cond. 4), except that the sources extend father aft. The summaries for Cond. 6 are given in Tables 11 and 12.

Beamforming images for Cond. 6 with a different array position are given in Figure 25. In this case, the array was parallel to the jet and separated from it by $2 \mathrm{~m}$, like the $90^{\circ}$ of the other plots. It was shifted upstream by $10 \mathrm{~d}(20 \mathrm{in}$.) so the aim point moved to the jet nozzle. This position gives clearer images of the shock cells, presumably because it is farther from the jet noise directivity peak cone, reducing the interfering noise from large scale, convecting, structures. Figure 25(a) shows a high frequency range, a subset of the $32 \mathrm{kHz} \mathrm{OB}$, using conventional beamforming with diagonal deletion. The shock cell structure can be seen, but not very clearly. Figure 25(b) shows the same case using TIDY. The shock structure is sharply defined. Figure 25 (c) presents the tone with conventional beamforming. The only source that can be seen within the $12 \mathrm{~dB}$ dynamic range of the plot comes from a middle region of the pipe. Applying TIDY with a $24 \mathrm{~dB}$ dynamic range reveals the shock cell screech sources and changes the details of the pipe source distribution (Fig. 25(d)). The screech sources look different from the shifted perspective because they are highly directional. It should be noted that applying conventional beamforming with a $24 \mathrm{~dB}$ dynamic range also shows some evidence of the screech sources, but they are not well resolved.

The appearance of distinct sources in Figure 25(d) provides an opportunity to demonstrate the ability of Beamform Interactive and TIDY to separate components. Creating a separate region of interest for each source and rerunning the code produces the results shown in Figure 25(e). The nozzle/pipe source is about $17 \mathrm{~dB}$ stronger than the source from the 2 nd shock cell and about $11 \mathrm{~dB}$ stronger than the source from the 8th shock cell. The interpretation is that the jet sources, together, act as a phased array that has a relative null in the direction of the acoustic sensor, but the pipe is a strong scatterer. The near agreement of the log sum of the component levels (trivial in this case because the pipe is dominant) with the array average is another validation of the approach. 


\section{OASPL Plots}

Since the TIDY algorithm is wide band, it is feasible to make beamforming plots over a very wide frequency range. Using a $12 \mathrm{~dB}$ dynamic range setting, this conceals some of the interesting structure seen in the octave band plots. In an effort to restore this structure, the dynamic range setting was increased to $30 \mathrm{~dB}$. The resulting plots show intriguing patterns of spots along lines that seem to be the jet boundary. The spots alternate between the upper and lower boundary lines, suggesting a helical structure. It is not known whether these are real, or whether they represent an array processing artifact. They appear at all conditions from the $90^{\circ}$ angle and never appear at the $40^{\circ}$ angle. Efforts to create such artifacts by simulation have not succeeded. Samples are shown in Figure 26.

\section{Conclusions}

Using a carefully designed and constructed two-dimensional planar phased array and the TIDY beamforming algorithm it has been possible to update the types of jet noise source images made in the 1970 s using mirrors. Some general trends have been duplicated: the peak source location moves forward with frequency, and a strong, high frequency source appears near the nozzle when imaging for a downstream angle in supersonic cases. As in the earlier work, the imaging protocol was validated by agreement between the integrated images and conventional single microphone levels. A significant difference between the two-source model deduced from the elliptic mirror (and other data) and the current results has emerged. The two source model calls for the large turbulent structure noise to emerge from the jet shear layer starting near the nozzle and for noise from fine scale turbulence to begin downstream of the of the potential core and to be distributed throughout the mixing region. The opposite is observed: the high frequency portion of the noise from fine scale turbulence (classified as the noise observed from $90^{\circ}$ ) appears to originate at the shear layer, and the large turbulent structure noise source is concentrated on the jet axis at high frequency and distributed in the jet at low frequency.

The phased array shows more details at once than the elliptic mirror because it performs twodimensional imaging, as opposed to zero-dimensional imaging with scanning for the elliptic mirror.

Images of an underexpanded, supersonic jet show the shock diamonds in detail at high frequency. The tone images show at least some of the multiple sound source locations involved in the production and subsequent propagation of screech.

Imaging from $40^{\circ}$, it appears to be possible to look inside the nozzle to see high frequency boundary layer noise.

Wide band, high dynamic range images from $90^{\circ}$ contain patterns of alternating spots along lines that could plausibly be the jet boundary.

\section{References}

1. Hubbard, H.H. Aeroacoustics of Flight Vehicles: Theory and Practice-Volume 1: Noise Sources. NASA, 1991.

2. Tam, C.K.W., K. Viswanathan, K.K. Ahuja, and J. Panda, "The sources of jet noise: experimental evidence," AIAA Paper 2007-3641, 2007.

3. Lele, S.J. "Phased array models of shock-cell noise sources," AIAA Paper 2005-2841, May, 2005.

4. Kandula, M. "Shock-refracted acoustic wave model for screech amplitude in supersonic jets," $A I A A$ Journal, Vol. 46, No. 3, 2008, pp. 682-689.

5. Viswanathan, M.B. Alkislar, and M. Czech, "Characteristics of the shock noise component of jet noise," AIAA Paper 2008-2835, May, 2008.

6. Veltin, J. and D.K. McLaughlin, "Noise mechanisms in shock containing screeching jets using optical deflectrometry," AIAA Paper 2008-2889, May, 2008.

7. Miller, S.A.E., J. Veltin, P.J. Morris and D.K. McLaughlin, "Validation of computational fluid dynamics for supersonic shock containing jets," AIAA Paper 2008-2988, May, 2008. 
8. Bodony, D.J., J. Ryu, and S.J. Lele, "Investigating broadband shock-associated noise of axisymmetric jets using large-eddy simulation," AIAA Paper 2006-2495, May, 2006.

9. Fisher, M.J., M. Harper-Bourne, and S.A.L. Glegg, "Jet noise source location: The Polar Correlation Technique," Journal of Sound and Vibration, Vol. 51, pp. 23-54, 1977.

10. Weir, D., J. Bridges, F. Agboola, and R. Dougherty, "Source Identification and Location Techniques," Proceedings of the Jet Noise Workshop, NASA/CP - 2001-211152, 479-506, 20011101, November 2001.

11. Suzuki, T., "New beam-forming algorithm for high speed jet flows," AIAA Paper No. 2002-2505.

12. Dougherty, R., J. Panda, and S. Lee, "Non-intrusive jet noise study combining Rayleigh scattering and phased array measurement techniques," AIAA-2005-2843, May, 2005.

13. Reba, R., S. Narayanan, T. Colonius and T. Suzuki, "Modeling Jet Noise from Organized Structures Using Near-Field Hydrodynamic Pressure," AIAA-2005-3093, May, 2005.

14. Papamoschou, D. and A. Dadvar, "Localization of Multiple Types of Jet Noise Sources," AIAA2006-2644, May, 2006.

15. Lee, S., "Phased-Array Study of Dual-Flow Jet Noise: Effect of Nozzles and Mixers," AIAA-2006 2647, May, 2006.

16. Suzuki, T. "Coherent Noise Radiation from a Jet Investigated with a Beam-Forming Technique," AIAA-2006-2646, May 2006.

17. Brusniak, L., J. Underbrink, E. Nesbitt, D. Lynch, and M. Martinez, "Phased Array Measurements of Full-Scale Engine Exhaust Noise," AIAA-2007-3612, May 2007.

18. Tester, B. and S. Glegg "A review of engine noise source diagnostic methods for static engine tests, with phased arrays and polar correlation techniques," AIAA-2008-2985, May 2008.

19. Michel, U., "Influence of source interference on the directivity of jet mixing noise," AIAA-20073648, May, 2007.

20. Laufer, J., R.H. Schlinker, and R.E. Kaplan, "Experiments on supersonic jet noise," AIAA Journal, Vol. 14, No. 4, 1976, pp. 489-497.

21. Blllingsley, J. and R. Kinns, "The acoustic telescope" Journal of Sound and Vibration, Vol. 48, No. 4 pp. 485-510, 1976.

22. Dougherty, R. P., "Beamforming in acoustic testing." Chapter 2 in Aeroacoustic Measurements, T.J. Mueller, ed., Springer-Verlag, 2002.

23. Ehrenfried, K. and L. Koop, "A Comparison of Iterative Deconvolution Algorithms for the Mapping of Acoustic Sources," AIAA Paper 2006-2711, 2006.

24. Sijtsma, P, "CLEAN Based on Spatial Source Coherence," AIAA-2007-3436, 2007.

25. Dougherty, R.P, “Advanced time-domain beamforming techniques," AIAA-2004-2955.

26. Dougherty, R.P, "Extensions of DAMAS and benefits and limitations of deconvolution in beamforming," AIAA-2005-2961.

27. Brown, C., and J. Bridges, "Small Hot jet Acousitc Rig Validation," NASA/TM-2006-214234, April, 2006.

28. Bridges, J., and C. Brown, "Parametric Testing of Chevrons on Single Flow Hot Jets," NASA/TM2004-213107, Sept. 2004.

29. Tam, C.K.W., N.N. Pastouchenko, and R.H. Schlinker, "On the two sources of supersonic jet noise," AIAA Paper 2003-3163, May, 2003.

30. Crighton, D.G. and P. Huerre, "Shear-layer pressure fuctuations and superdirective acoustic sources," J. Fluid Mech., Vol. 220, pp. 355-368, 1990.

31. Tam C.K.W. and D.E. Burton, "Sound generated by instability waves of supersonic flows. Part 2. Axisymmetric jets," J. Fluid Mech. Vol. 138, pp. 249-295, 1984. 


\begin{tabular}{|c|c|c|}
\hline \multicolumn{2}{|c|}{ REPORT DOCUMENTATION PAGE } & $\begin{array}{l}\text { Form Approved } \\
\text { OMB No. 0704-0188 }\end{array}$ \\
\hline \multicolumn{3}{|c|}{ 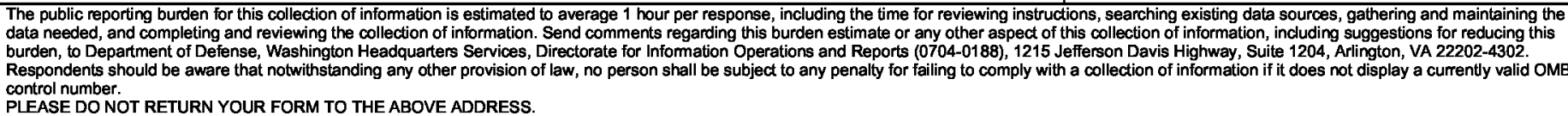 } \\
\hline $\begin{array}{l}\text { 1. REPORT DATE (DD-MM-YYYY) } \\
01-03-2010\end{array}$ & $\begin{array}{l}\text { 2. REPORT TYPE } \\
\text { Technical Memorandum }\end{array}$ & 3. DATES COVERED (From - To) \\
\hline \multirow{3}{*}{\multicolumn{2}{|c|}{$\begin{array}{l}\text { 4. TITLE AND SUBTITLE } \\
\text { Improved Phased Array Imaging of a Model Jet }\end{array}$}} & $\begin{array}{l}\text { 5a. CONTRACT NUMBER } \\
\text { NNC07CB02C }\end{array}$ \\
\hline & & 5b. GRANT NUMBER \\
\hline & & 5c. PROGRAM ELEMENT NUMBER \\
\hline \multirow{3}{*}{\multicolumn{2}{|c|}{$\begin{array}{l}\text { 6. AUTHOR(S) } \\
\text { Dougherty, Robert, P.; Podboy, Gary, G. }\end{array}$}} & 5d. PROJECT NUMBER \\
\hline & & 5e. TASK NUMBER \\
\hline & & $\begin{array}{l}\text { 5f. WORK UNIT NUMBER } \\
\text { WBS 561581.02.08.0318.02 }\end{array}$ \\
\hline \multicolumn{2}{|c|}{$\begin{array}{l}\text { 7. PERFORMING ORGANIZATION NAME(S) AND ADDRESS(ES) } \\
\text { National Aeronautics and Space Administration } \\
\text { John H. Glenn Research Center at Lewis Field } \\
\text { Cleveland, Ohio } 44135-3191\end{array}$} & $\begin{array}{l}\text { 8. PERFORMING ORGANIZATION } \\
\text { REPORT NUMBER } \\
\text { E-17214 }\end{array}$ \\
\hline \multirow{2}{*}{\multicolumn{2}{|c|}{$\begin{array}{l}\text { 9. SPONSORING/MONITORING AGENCY NAME(S) AND ADDRESS(ES) } \\
\text { National Aeronautics and Space Administration } \\
\text { Washington, DC 20546-0001 }\end{array}$}} & $\begin{array}{l}\text { 10. SPONSORING/MONITOR'S } \\
\text { ACRONYM(S) } \\
\text { NASA }\end{array}$ \\
\hline & & $\begin{array}{l}\text { 11. SPONSORING/MONITORING } \\
\text { REPORT NUMBER } \\
\text { NASA/TM-2010-216227 }\end{array}$ \\
\hline \multicolumn{3}{|c|}{$\begin{array}{l}\text { 12. DISTRIBUTION/AVAILABILITY STATEMENT } \\
\text { Unclassified-Unlimited } \\
\text { Subject Category: } 71 \\
\text { Available electronically at http://gltrs.grc.nasa.gov } \\
\text { This publication is available from the NASA Center for AeroSpace Information, 443-757-5802 }\end{array}$} \\
\hline
\end{tabular}

\section{SUPPLEMENTARY NOTES}

\section{ABSTRACT}

An advanced phased array system, OptiNav Array 48, and a new deconvolution algorithm, TIDY, have been used to make octave band images of supersonic and subsonic jet noise produced by the NASA Glenn Small Hot Jet Acoustic Rig (SHJAR). The results are much more detailed than previous jet noise images. Shock cell structures and the production of screech in an underexpanded supersonic jet are observed directly. Some trends are similar to observations using spherical and elliptic mirrors that partially informed the two-source model of jet noise, but the radial distribution of high frequency noise near the nozzle appears to differ from expectations of this model. The beamforming approach has been validated by agreement between the integrated image results and the conventional microphone data.

\section{SUBJECT TERMS}

Acoustics; Jet noise; Phased arrays; Beamforming

\begin{tabular}{|c|c|c|c|c|c|}
\hline \multicolumn{3}{|c|}{ 16. SECURITY CLASSIFICATION OF: } & \multirow{2}{*}{$\begin{array}{l}\text { 17. LIMITATION OF } \\
\text { ABSTRACT } \\
\text { UU }\end{array}$} & \multirow{2}{*}{$\begin{array}{l}\text { 18. NUMBER } \\
\text { OF } \\
\text { PAGES } \\
34\end{array}$} & \multirow{2}{*}{$\begin{array}{l}\text { 19a. NAME OF RESPONSIBLE PERSON } \\
\text { STI Help Desk (email:help@sti.nasa.gov) } \\
\text { 19b. TELEPHONE NUMBER (include area code) } \\
\text { 443-757-5802 }\end{array}$} \\
\hline $\begin{array}{l}\text { a. REPORT } \\
\text { U }\end{array}$ & $\begin{array}{l}\text { b. ABSTRACT } \\
\text { U }\end{array}$ & $\begin{array}{l}\text { c. THIS } \\
\text { PAGE } \\
\text { U }\end{array}$ & & & \\
\hline
\end{tabular}



